\title{
The Impact of Western Diet and Nutrients on the Microbiota and Immune Response at Mucosal Interfaces
}

\author{
Donjete Statovci ${ }^{1}$, Mònica Aguilera ${ }^{1}$, John MacSharry ${ }^{1,2}$ and Silvia Melgar ${ }^{1 *}$ \\ ${ }^{1}$ APC Microbiome Institute, University College Cork, Cork, Ireland, ${ }^{2}$ School of Microbiology, University College Cork, \\ Cork, Ireland
}

Recent findings point toward diet having a major impact on human health. Diets can either affect the gut microbiota resulting in alterations in the host's physiological responses or by directly targeting the host response. The microbial community in the mammalian gut is a complex and dynamic system crucial for the development and maturation of both systemic and mucosal immune responses. Therefore, the complex interaction between available nutrients, the microbiota, and the immune system are central regu-

OPEN ACCESS

Edited by:

Raquel Hontecillas,

Virginia Tech, United States

Reviewed by:

Mourad Aribi,

University of Tlemcen, Algeria

Christopher Alan Jolly,

University of Texas at Austin,

United States

*Correspondence:

Silvia Melgar

s.melgar@ucc.ie

Specialty section: This article was submitted to Nutritional Immunology, a section of the journal Frontiers in Immunology

Received: 31 January 2017 Accepted: 03 July 2017

Published: 28 July 2017

Citation:

Statovci D, Aguilera M, MacSharry J and Melgar S (2017) The Impact

of Western Diet and Nutrients on the Microbiota and Immune Response at Mucosal Interfaces.

Front. Immunol. 8:838. doi: 10.3389/fimmu.2017.00838 lators in maintaining homeostasis and fighting against invading pathogens at mucosal sites. Westernized diet, defined as high dietary intake of saturated fats and sucrose and low intake of fiber, represent a growing health risk contributing to the increased occurrence of metabolic diseases, e.g., diabetes and obesity in countries adapting a westernized lifestyle. Inflammatory bowel diseases (IBD) and asthma are chronic mucosal inflammatory conditions of unknown etiology with increasing prevalence worldwide. These conditions have a multifactorial etiology including genetic factors, environmental factors, and dysregulated immune responses. Their increased prevalence cannot solely be attributed to genetic considerations implying that other factors such as diet can be a major contributor. Recent reports indicate that the gut microbiota and modifications thereof, due to a consumption of a diet high in saturated fats and low in fibers, can trigger factors regulating the development and/or progression of both conditions. While asthma is a disease of the airways, increasing evidence indicates a link between the gut and airways in disease development. Herein, we provide a comprehensive review on the impact of westernized diet and associated nutrients on immune cell responses and the microbiota and how these can influence the pathology of IBD and asthma.

\section{Keywords: westernized diet, inflammatory bowel disease, asthma, saturated fat, micronutrients, microbiota}

\section{GENERAL INTRODUCTION}

The prevalence of chronic inflammatory diseases affecting mucosal sites such as the intestine and the airways is increasing worldwide $(1,2)$. Among these, inflammatory bowel disease [IBD, mainly comprising ulcerative colitis (UC) and Crohn's Disease (CD)] and allergic asthma are the most relevant. Recent findings point toward potential links between these two pathologies, e.g., histamine and mast cell activity and immunoglobulin E (IgE) production, reviewed in Ref. (3). Both diseases have a 
multifactorial cause, in which environmental factors such as diet and the commensal microbiota are gaining increased attention. In this regard, consumption of the so-called "Westernized" diet is associated with increased risk for IBD (4) and asthma morbidity (5). Westernized diet is characterized by a high content of proteins (derived from fatty domesticated and processed meats), saturated fats, refined grains, sugar, alcohol, salt, and corn-derived fructose syrup, with an associated reduced consumption of fruits and vegetables $(4,6,7)$. Research in the last decade has uncovered that changes from a diet rich in fibers and low in fats to a diet low in fibers and high in saturated fats directly contributes to the development of obesity, metabolic syndrome, and cardiovascular diseases $(8,9)$. Macronutrients (carbohydrates, lipids, and protein) and micronutrients (vitamins and minerals) are required for our body to function and several of these are naturally obtained from our diets and from the resident microbiota. Both patients with IBD and asthma present nutritional problems leading to several complications including anemia, osteoporosis, acute respiratory infections, etc. The link between diet, nutrients and immune responses is embedded in a complex network of signals and has to be considered in the light of other factors including microbial composition, genetic background, and lifestyle, to mention but a few. The advent of high-throughput Next-Generation Sequencing technologies has driven the discovery and dissection of regulatory mechanisms involved in the disease state. In this review, we will focus on the interactions between diets and nutrients associated with Westernized regimes and their impact on the microbiota and immune responses at mucosal interfaces, i.e., the intestines and lungs. We will outline the complex network between nutrients, microbial alterations and abnormal immune responses associated with IBD and asthma.

Table 1 summarizes the impact of dietary factors on host responses. Figure 1 summarizes identified genes associated with IBD and asthma and immune responses. Figure 2 displays the regulatory interaction between diet, mucosal immunity, and commensal microbiota to maintain mucosal homeostasis and the resulting pathology upon loss of balance. Figures 3 and 4 outline the mechanisms targeted by nutrients in the healthy intestine and lung and in the inflamed gut (IBD) and lung (asthma), respectively.

\section{IBD-GENETICS, IMMUNE RESPONSE, AND MICROBIOTA}

Inflammatory bowel diseases are multifactorial chronic immunemediated diseases of the gastrointestinal (GI) tract. They often have an early onset and a course which is characterized by intermittent phases of remission and relapses $(42,43)$. Nearly 2.2 million people in Europe, 1.5 million Americans, and several 100,000 more individuals suffer from IBD. The prevalence and incidence of IBD is increasing worldwide and its growth is not confined to Western Europe or the USA; countries adapting a westernized lifestyle, such as Japan and South Africa, are seeing mounting numbers of affected individuals (2). Patients suffering from IBD present symptoms such as abdominal pain, fever, and diarrhea with blood and/or mucus excretion. Antibiotics, biologics, corticosteroids, and immune modulators are the current treatments of choice for patients with IBD, with the overall goal being inflammation reduction, increase of mucosal healing and symptom relief $(16,44)$. New treatment strategies include inhibitors targeting leukocyte trafficking ( $\alpha 4 \beta 7$ integrin, sphingosine-1-phosphate, $\mathrm{S} 1 \mathrm{P})$, cytokine [interleukin (IL)-12p40, IL-23], janus kinasepathway, inflammasome (NLRP3/IL-1 $\beta)$, to name a few $(45,46)$. The etiology of IBD is still unknown but the evidence points toward environmental factors, with the microbiota being of particular interest. The microbiota can trigger and/or sustain a tissue damaging immune response in genetically susceptible individuals. Research in the last decade has identified a crucial role for the commensal bacteria in the pathogenesis of IBD. Experimental IBD was not evidenced in animals raised under germ-free (GF) conditions when compared to groups of conventionalized animals (47). Antibiotics have proven beneficial to certain subgroups of patients with CD but not in patients with UC (48) and inflammatory lesions are more frequently located in areas with large bacterial burden, i.e., ileum and colon (49). Alterations in the enteric microbial flora reported in patients with IBD include decreases in Firmicutes and Bacteroidetes and increases in Enterobacteriaceae (e.g., Escherichia coli) (50). A reduction in anti-inflammatory commensals, such as Faecalibacterium prausnitzii has been associated with CD (51). Several pathogenic bacteria are suggested as etiological agents of IBD but to date none has been identified to cause IBD (47). In contrast, pathobionts, i.e., commensal bacteria with potential pathological properties, have been isolated, including strains of adherent and invasive E. coli (AIEC), commonly identified in the mucosa of CD patients (52).

Genome-wide association studies have so far identified over 160 genetic loci in IBD, with 30 loci being specific to $C D, 23$ loci to UC, and 110 loci are associated with both forms of IBD (53). IBD susceptibility single-nucleotide polymorphisms were identified in genes affecting innate and adaptive immune cell function, bacterial recognition, etc. (Figure 1). Therefore, the role of mononuclear phagocytes including monocytes/macrophages and dendritic cells (DCs) in the development of IBD has been extensively studied. Several mouse models of IBD, including dextran sodium sulfate (DSS)- and 2,4,6-trinitrobenzene sulfonic acid-induced colitis and the TNF $\triangle$ ARE model of Crohn's-like ileitis, have revealed that lamina propria mononuclear phagocytes have protective as well as pathogenic roles during the disease progression (54-60). Three explanations have been postulated to explain these findings-(1) an inappropriate response to nonharmful commensal bacteria (i.e., NOD2, REL, CARD9); (2) an inefficient clearance of microbes (commensals/pathobionts) leading to chronic immune stimulation (i.e., ATG16L1, IRGM), and (3) a failure to resolve inflammation by maintaining a proinflammatory phenotype (i.e., IL-12, IL-18RAP/IL-1R1, IFNGR/ IFNAR1) (39) (Figure 1). The intestinal epithelium functions as a barrier between the host and its environment (microbes, nonself-antigens from diet, nutrients, etc.) and consists of highly specialized cells that fulfill this barrier task. Genes associated with epithelial cell function, such as HNF4A, ECM1, CDH1 have a UC correlation (53) (Figure 1). Alterations in barrier integrity associated with IBD include decreased structure of tight-junction (TJ) proteins, which regulate paracellular permeability, impaired 
mucus production due to loss of goblet cells and an altered production of antimicrobial peptides (61) (Figure 4).

In terms of location, CD can affect any part of the GI tract from the mouth to rectum. However, in the majority of patients with CD the inflammation is localized to the distal ileum and proximal colon (62). The inflammation in CD is patchy and often transmural, which can lead to the development of fibrosis, fistulas, fissures, strictures, etc. A dense infiltration with macrophages and lymphocytes and granuloma formation is a typical feature of the disease. Patients with CD present an imbalanced immune response with high expression of innate pro-inflammatory cytokines, including IL-1 $\beta$, IL-6, and tumor necrosis factor (TNF)- $\alpha$ and a T helper (Th)1 (IL-12-mediated interferon (IFN) $\gamma$ ) and Th17 (IL-17a) profile resulting in an enhanced and uncontrolled immune response $(16,43,62)$ (Figure 4). In contrast to $\mathrm{CD}, \mathrm{UC}$ is restricted to the mucosa of the colon and is associated with large infiltrates of neutrophils, $\mathrm{T}$ and $\mathrm{B}$ cells in the lamina propria. Characteristically, the inflammation originates in the rectum extending continuously in a proximal fashion. Crypt abscesses, formed by extravasation of neutrophils through the intestinal epithelium, ulcerations, and goblet cell loss are typical features of UC. Moreover, high levels of innate cytokines, including IL-1 $\beta$, IL- 6 , and TNF $\alpha$, and chemokines, such as CXCL8 and GRO $\alpha / C X C L 1$ (neutrophil attractants), as well as an atypical Th2 cytokine profile accompanied by high production of IL-5, IL-10, transforming growth factor beta (TGF $\beta$ ) and only initially IL-4 production, which is superseded by IL-13 production is associated to patients with UC (62-65) (Figure 4).

\section{ASTHMA-GENETICS, IMMUNE RESPONSE, AND MICROBIOTA}

Asthma is an increasingly common heterogeneous chronic inflammatory disease, which places substantial burden on patients, their families, and the community (66). Asthma is characterized by airway immune hyper responsiveness to inhaled environmental particles leading to wheezing, breathlessness, chest tightness, and coughing effecting airway function (http://ginasthma.org/). Worldwide the incidence of asthma, is increasing, with an estimated 300 million affected individuals (http://ginasthma.org/). Once thought to be a childhood disease it is now presenting in respiratory clinics as first time adult onset asthma.

Asthma presents with airway inflammation following exposure to insults such as allergens, pollutants, and microbes (67). The primary site of immune induction is initially the lung epithelium, which interacts with the underlying antigen presenting cells such as DCs, inducing an immune response (Figure 4). Alveolar macrophages in the airway lumen act as clearance and immune sampling mechanisms at the interface between the mucosa and the external environment (68). The immune signaling from epithelial cells and macrophages results in secretion of first order cytokines, such as CXCL8, IFN $\alpha$, IL-1 $\beta$, IL-33, TGF $\beta$, and thymic stromal lymphopoietin (TSLP), which induce a rapid immune trafficking and a clearance response which subsequently results in second order cytokine secretion by T cells (69). Activated DCs migrate to the lymph nodes and induce $\mathrm{T}$ cell activation (70) (Figure 4). The subsequent $\mathrm{T}$ cell immune response can result in either an allergenic Th2/eosinophilic IgE-mediated inflammation or an inflammatory Th1/neutrophilic cell influx into the airway. The Th2 allergenic response involves the interaction of DCs, Th2 cells, and IL-4 producing basophils which induce the expansion of type 2 innate lymphoid cells (ILC2) which also produce the Th2 cytokines, IL-5, IL-9, and IL-13, leading to eosinophil and mast cell trafficking to the lung and goblet cell mucus secretion (70) (Figure 4). IL-4 derived from Th2 cells also induces IgE production by B cells. The mixed Th2 and Th1 neutrophilic or Th2 low asthma is induced by toll-like receptor (TLR) activation resulting in IL-1 $\beta$ secretion and activation of inflammatory Th1 and Th17 cells. These cells release IL-17a and IFN $\gamma$, which activate neutrophils and macrophages to release TNF $\alpha$ and induce inflammatory signals. The resulting immune infiltrates induces the symptoms of asthma-bronchoconstriction, mucus production, and the resultant tissue remodeling increasing smooth muscle and collagen deposition $(71,72)$. The subsequent remodeling results in airway wall thickening, compromised lung function and changes in the lung microbiota $(41,73)$. The mechanisms of asthma have been studied successfully over the decades using murine models, such as the ovalbumin and the house dust mite challenge models (74). While all models have limitations, these studies have led to successful therapy development and understanding of the genetics of asthma (75). Asthma treatment targets immune processes by using inhaled corticosteroids, to reduce inflammation, and bronchodilators to counteract the effects of bronchoconstriction induced by the release of histamine, prostaglandins, interleukins, or leukotrienes.

Several genetic studies have identified asthma susceptibility genes, including IRAK3, SMAD3, ORMDL3, IL-1RL1, IL-13, IL-33, TNFAIP3, and TSLP (76) (Figure 1). Recent studies have highlighted the role of the site of the mutation and allele frequency and the particular site of functionality, such as the asthmatic epithelium, and the epigenetic regulation thereof as being key factors contributing to asthma $(77,78)$. Studies on DNA methylation, and microRNA modulation of gene expression, are now shedding light on the pathogenesis of this multifactorial disease.

There is increasing evidence that the gut plays a key role in effecting the allergic immune response. Murine models have demonstrated how feeding of gut commensals can reduce allergy symptoms by inducing $\mathrm{T}$ regulatory cells (Tregs) which migrate to the lung and reduce the immune response $(79,80)$. Indeed, antibiotic-mediated disruption of the gut microbiota and mycobiota has been shown to exacerbate allergic asthma symptoms in mice $(81,82)$. Recently, an elegant study by Arrieta and colleagues found that the relative abundance of the bacterial genera Faecalibacterium, Lachnospiria, Veillonella, and Rothia and Clostridium neonatale are decreased in the gut of children at risk of asthma development $(83,84)$. These microbes were significantly different between the groups at 3 months of age and the difference decreased as children reached 1 year of age highlighting a colonization window of opportunity and of an appropriate immune education. 


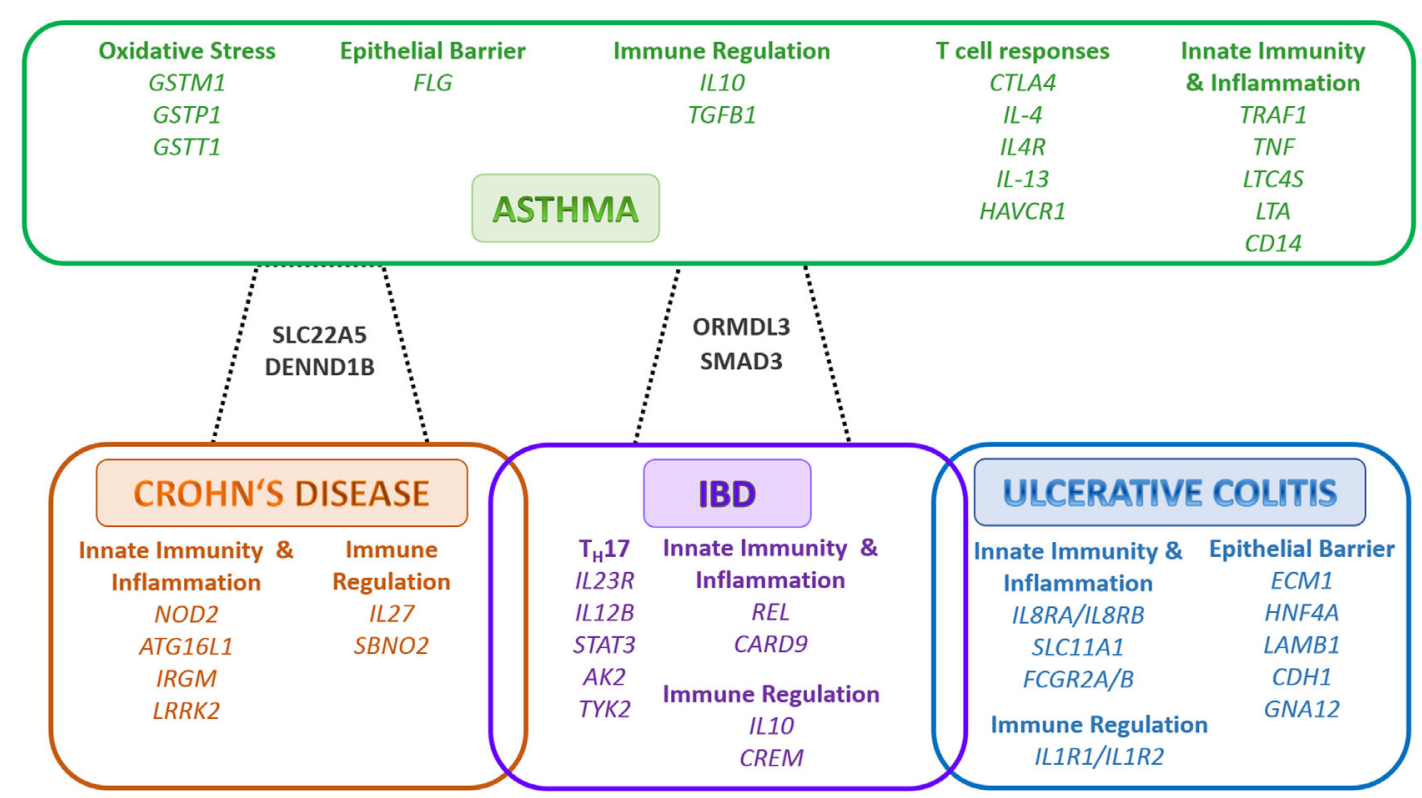

FIGURE 1 | Shared and individual inflammatory bowel disease (IBD) and Asthma susceptibility genes/loci. The outlined genes are grouped according to function. In green color are the genes associated to asthma, in blue color are the genes associated to ulcerative colitis only, in orange color are the genes associated to Crohn's disease only, in purple color are the genes associated to IBD, in black color are the genes associated to asthma and Crohn's disease or asthma and IBD, respectively. Adapted from Ref. (37-40). Abbreviations: AK2, adenylate kinase 2; ATG16L1, autophagy related 16 like 1; CARD9, caspase recruitment domain family member 9; CD14, cluster of differentiation 14; CDH1, cadherin 1; CREM, CAMP responsive element modulator; CTLA4, cytotoxic T-lymphocyte associated protein 4; DENND1B, DENN domain containing 1B; ECM1, extracellular matrix protein 1; FCGR2A, FC fragment of IgG receptor lla; FCGR2B, FC fragment of IgG receptor Ilb; FLG, filaggrin; GNA12, G-protein subunit alpha 12; GSTM1, glutathione S-transferase mu 1; GSTP1, glutathione S-transferase pi 1; GST1, glutathione S-transferase theta 1; HAVCR1, hepatitis A virus cellular receptor 1; HNF4A, hepatocyte nuclear factor 4 alpha; IL-13, interleukin 13; IL-4, interleukin 4; IL-10, interleukin 10; IL-12B, interleukin 12B; IL-1R1, interleukin 1 receptor type 1; IL-1R2, interleukin 1 receptor type 2; IL23R, interleukin 23 receptor; IL-27, interleukin 27; IL-4R, interleukin 4 receptor; CXCR1, C-X-C motif chemokine receptor 1; CXCR2, C-X-C motif chemokine receptor 2; IRGM, immunity related GTPase M; LAMB1, laminin subunit beta 1; LRRK2, leucine rich repeat kinase 2; LTA, lymphotoxin alpha; LTC4S, leukotriene C4 synthase; NOD2, nucleotide binding oligomerization domain containing 2; ORMDL3, ORMDL sphingolipid biosynthesis regulator 3; REL, REL proto-oncogene, NF-kB subunit; SBNO2, strawberry notch homolog 2; SLC11A1, solute carrier family 11 member 1; SLC22A5, solute carrier family 22 member 5; SMAD3, SMAD Family Member 3; STAT3, signal transducer and activator of transcription 3; Th, T helper cell; TGFB1, transforming growth factor beta 1; TNF, tumor necrosis factor; TRAF1, TNF receptor associated factor 1; TYK2, tyrosine kinase 2

\section{REGULATION OF MICROBIOTA BY DIET}

Diet has a major impact on human health, whether by affecting the host directly or through changes of the microbial community. The microbial community in the mammalian gut is a complex and dynamic system with a steady state (85), which can be perturbed by many environmental factors, including diet, lifestyle, drugs, thereby changing the host's physiology $(10,86)$ (Figure 2). As a response to dietary changes, shifts in the composition of the gut microbiota occur. Especially during early-life events like weaning off and introduction to solid food, the dynamics of colonization are critically involved in educating as well as training the immune system (87). The consumption of a Westernized diet containing excessive amounts of refined and processed foods, red meats, and sugary beverages, accompanied with a low consumption of fibers, fruits, and vegetables, is associated with the increased occurrence of metabolic diseases, such as diabetes and obesity, both of which are associated with systemic low-grade inflammation attributed to endotoxemia $(88,89)$ (Figure 2B). A healthy gut microbiota maintains a symbiotic relationship within the gut mucosa offering essential functions in metabolism, immunology, and protection of the host (Figure $2 \mathrm{~A}$ ). The commensal microbiota, consisting of up to $1 \times 10^{14}$ bacteria, confers colonization resistance against pathogens, which is a key host defense mechanism against enteric infections. Commensal microbes occupy niches and exhaust nutrients thereby limiting the growth of newcomers. Dietary changes, inflammation, and antibiotics can disrupt the commensal microbial community and hence increase the risk of colonization and expansion of incoming pathogens (90). The commensal microbiota is also essential for the elimination of pathogens from the gut. For example, unlike conventional specific pathogen free mice, GF mice are unable to eradicate enteric pathogens such as Citrobacter rodentium from the gut (19). Therefore, the abundance and diversity of microbial members plays a crucial role in fulfilling these functions, i.e., symbiosis, colonization resistance, clearance of pathogens, etc. Decreased microbial diversity or altered composition, e.g., increased Firmicutes to Bacteroidetes ratio, entail various health risks for the host and are generally associated to poor health (91). Feeding high-fat and high sucrose diet to wild-type (WT) mice leads to decreased gut microbiota diversity and an increase in opportunistic pathogens, resulting in a decreased prevalence 
of specific gut barrier-protective bacteria (92). However, reverting the animals to regular chow food reverses the dietary perturbations thereby confirming the structural resilience of the gut microbiota. Similarly, the human microbiota can rapidly adapt to dietary changes $(93,94)$. A comparative analysis of vegan, vegetarian, and omnivore diets and the corresponding shifts in microbial communities revealed that a significant increase in $\beta$-diversity was present as quickly as $24 \mathrm{~h}$ post switch to the animal-based diet (93). These findings suggest that changes in environmental conditions of gut microbiota, e.g., through changes in diet, put selective pressure on various species, which in turn leads to competition for the most adaptable bacteria to survive and replicate (7).

\section{DIET AND IMMUNE RESPONSES IN THE ADIPOSE TISSUE}

The adipose tissue is an active endocrine and secondary immune organ consisting of adipocytes, immune cells ( $\mathrm{T}$ cells and macrophages) and connective/nerve tissue which produces hormones including adipokines [such as leptin and resistin (pro-inflammatory) and adiponectin (anti-inflammatory)], cytokines, and chemokines. The adipose tissue in lean individuals is characterized by an anti-inflammatory cytokine and adipokine profile (e.g., IL-4, IL-10, IL-33, adiponectin) produced by M2 macrophages and Tregs, while obese mice present an initial $\mathrm{CD}^{+} \mathrm{T}$ cell infiltration followed by macrophages resulting in a pro-inflammatory (Th1/Th17 and M1) profile. M1 macrophages secrete pro-inflammatory cytokines, including TNF $\alpha$, IL-1 $\beta$, and IL-6 (95). Although a correlation between obesity and IBD is not confirmed [reviewed in Ref. (96)], the cytokine profile of the adipose tissue in patients with IBD and especially in CD patients, is similar to obese individuals exhibiting increased levels of TNF $\alpha$, IL- 6 and leptin and a reduction in adiponectin (97-100). CD adipocytes express TLRs, display a higher presence of commensal bacteria (Enterococcus faecalis) and an increased translocation of intestinal bacteria resulting in an increased C-reactive protein production (101). These findings indicate that adipocytes participate in the antimicrobial response and represent a barrier to maintain homeostasis and link the adipose tissue with innate immune responses (102). A typical feature of patients with CD is an enlarged mesenteric tissue wrapped around the intestine, so-called "creeping fat." This fat is usually found adjacent to inflammatory lesions, it correlates with disease activity, is characterized by high infiltration of lymphocytes and macrophages, high levels of peroxisome proliferator-activated receptor $\gamma(\operatorname{PPAR} \gamma)$ and TNF $\alpha$ and fibrosis (103-105). PPAR $\gamma$ is a nuclear receptor that controls the expression of a large number of regulatory genes in lipid metabolism, insulin sensitization, inflammation, and cell proliferation (106, $107)$ and can inhibit the activation of nuclear factor $\kappa B(\mathrm{NF} \kappa \mathrm{B})$, mitogen-activated protein kinase (MAPK), and cyclooxygenase 2 (COX-2) pathways leading to reduction of pro-inflammatory mediators (cytokines and prostaglandins). These findings indicate that mesenteric obesity may play an important role in CD pathogenesis. Contrary to IBD, an association between obesity and asthma, with increased asthma disease severity, has been specifically identified in children. Obesity appears to increase injury in the lungs of asthmatic patients by increasing eosinophil numbers to the airway wall and the systemic production of pro-inflammatory cytokines TNF $\alpha$, IL-6, IL-1 (5). A recent publication highlighted a pathogenic role for IL-17a produced from ILC3 cells in airways disease in mice with diet-induced obesity. This was accompanied by NLRP3 inflammasome and IL-17a activation in the adipose tissue and the lungs, leading to the identification of a new inflammasome/Th17 mechanism in asthma (108). Similarly to IBD, a reduction in adiponectin levels has also been reported, which can affect the anti-inflammatory immune function in asthma patients (5).

\section{DIETARY PATTERNS IN IBD AND ASTHMA}

Dietary nutrients shape the intestinal environment by having a crucial impact on intestinal microbial populations and immune responses. To date, epidemiological evidence from observational studies indicate that intake of fiber rich food, such as fruits and vegetables, can protect against IBD and asthma. Conversely, this protective effect has not been confirmed in randomized controlled trials. Recently, the evidence for the airway and gut microbiota in effecting asthma development and induction is mounting. Timing of neonatal exposure to microbes and the diversity of the exposing environment and gut metabolites appear to effect asthma development (83). In a seminal work by Gevers et al., microbial alterations in naïve treated pediatric CD patients were correlated with certain microbes, specific location and effect of antibiotic treatment-findings that can pave the way for new CD diagnostic tools (109). The effect of dietary habits on the early development of these diseases is yet to be discovered. In the next section, we summarize studies covering different dietary patterns and their contribution to disease status. For a more comprehensive review on dietary advice and interventions see recent reviews $(27,110-112)$.

\section{Fat and Sucrose}

A recent report from the European Prospective Investigation in Cancer (EPIC) study, did not identify a correlation between body mass index (a measure of obesity) and IBD morbidity (113), therefore proposing that a hypercaloric diet per se is not enough to trigger the development of IBD. Epidemiological studies indicate an increased risk of IBD is associated with a higher consumption of red and/or processed meat, dietary fat [especially n-6 polyunsaturated fatty acids (PUFAs)] and low levels of vitamin D (VitD) $(4,114,115)$. In addition, an association between disease activity and intake of total fat [trans, saturated, and monounsaturated fatty acids (MUFAs)] and a high n-6/n-3 PUFA ratio has been identified in patients with CD (116). Also, a direct correlation of colonic cytokine levels with saturated fatty acids (SFA) was identified in patients with UC (115). Similarly to IBD, the quality of fatty acids (FAs) appear also to effect the asthma response as trans FAs margarine (a trans FA source), n-6 FAs intake, and oleic acid intake are associated with increased asthma risk $(117,118)$. In addition to saturated fats, a higher prevalence and preference 


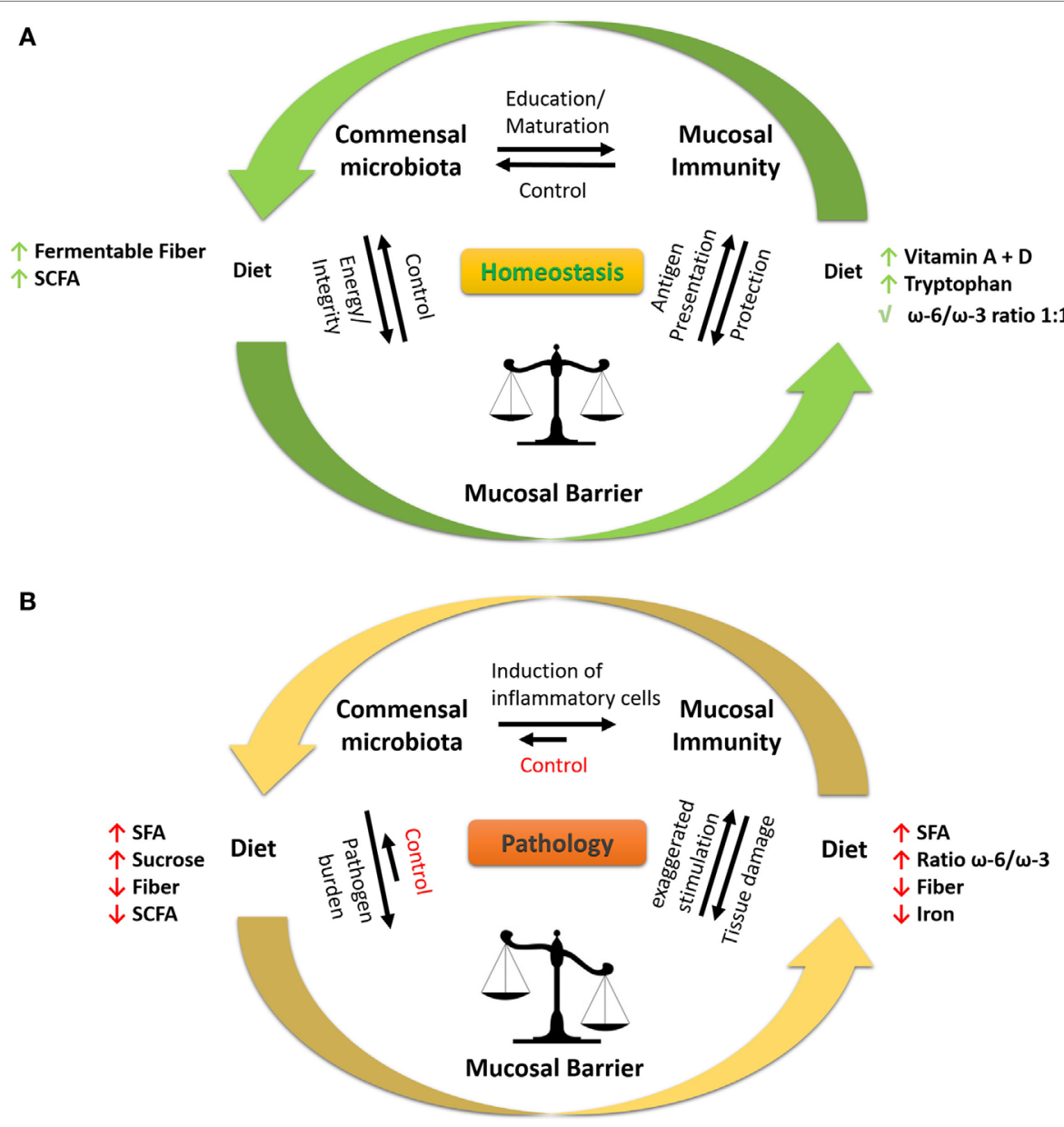

FIGURE 2 | Interaction between diet, microbiota, and immune response at mucosal sites. (A) To keep a healthy state, the local microbiota and mucosal immune system are in homeostasis at mucosal sites. The microbiota educates and promotes the maturation of the immune system by induction of pro-inflammatory and anti-inflammatory immune cells, e.g., Th17 (SFB), T regulatory cells (Clostridia spp.), and Th1 (Bacteroides fragilis). Moreover, the immune system surveys microbial activities (e.g., antigen sampling at the mucosal barrier) and responds in a controlled fashion by producing, e.g., antimicrobial peptides, slgA to prevent tissue damage. The integrity of the mucosal barrier is sustained by bacteria-produced metabolites (e.g., SCFA) such as butyrate resulting in high expression of tightjunction proteins and mucus production, thereby restricting interaction of microbes to the lumen and luminal epitheliums. The diet is involved in all processes, serving the microbiome with fermentable fibers and the immune system and epithelium with essential nutrients, e.g., vitamins and minerals. (B) During pathological conditions, such as inflammatory bowel disease and asthma, the homeostasis at the mucosal barrier is disrupted. A westernized diet, i.e., high in SFA, high $\omega-6 / \omega-3$ ratio, high sucrose and iron (oral iron supplements), and low in fiber promotes inflammation and growth of pathogenic/pathobiont (disease causing) bacteria in the gut. The microbiota, which is rich in non-beneficial bacteria, favorably induces the maturation of pro-inflammatory immune cells, leading to uncontrolled inflammation resulting in tissue damage of the mucosal compartment. The damaged mucosa and shifted immune response fail to control the microbiota, which exaggerates the pathophysiological state. Under certain conditions, bacteria-derived LPS enters the systemic circulation and further stimulates the immune system toward a pro-inflammatory state. Abbreviations: LPS, lipopolysaccharide; SCFAs, short-chain fatty acids; SFAs, saturated fatty acids; SFB, segmented filamentous bacteria; slgA, secretory immunoglobulin A; $\omega-6 / \omega-3$, omega-6/omega-3 fatty acid ratio; Th, T helper.

for foods with high calories, i.e., from fat and sucrose, has been linked to the worldwide increase in metabolic diseases (119). In IBD, one of the first studies that related sucrose to the development of CD was published four decades ago (120). More recently, the EPIC study uncovered an association between high consumption of sugar and soft drinks accompanied by a low vegetable intake to a higher UC risk (121). Similarly, high sugar consumption in sweetened beverages has been linked to asthma and dental caries which is also increased in asthmatics $(18,21,122)$. Studies in experimental models, e.g., transgenic CEABAC10 mice fed a diet high in fat and sucrose, resulted in altered microbiota composition, particularly in the expansion of and colonization of AIEC and reduction in protective bacteria, increased permeability and colonic pro-inflammatory mediators (Figure 4), and reduction in short-chain fatty acids (SCFA) concentrations and the SCFA receptor GPR43, supporting a role of fat and sucrose in exacerbating inflammation due to changes in microbial composition $(20,123)$. Overall, the studies to date indicate that a diet rich in saturated fat and high sucrose content presents a risk factor for IBD and asthma and is associated to inflammation while results from MUFA-containing diets are contradictory. 


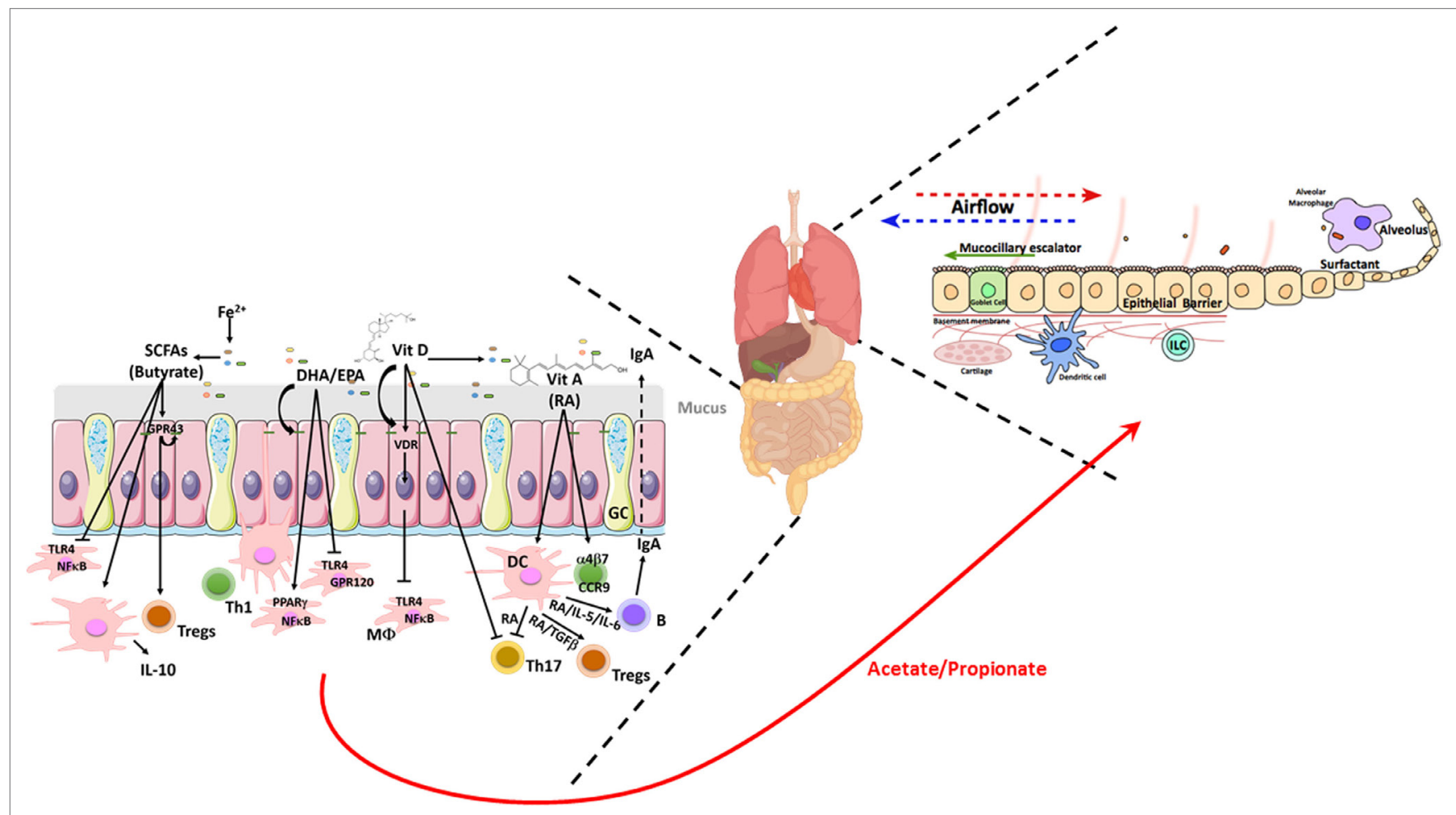

FIGURE 3 | Schematic illustrating the nutrient factors regulating microbial and host responses in the healthy gut and lung. Homeostatic balance at the mucosa due to a balanced diet rich in fiber allows for regulated interactions between the epithelia and the microbiome. This dialog with the microbiome allows for appropriate epithelial barrier function, mucus secretion, and underlying immune sensing. In the gut, a balanced microbiome generates SCFAs and dietary long chain FAs and the fat-soluble vitamins $A$ and $D$ which induce a tolerogenic mucosal immune state locally at the gut but also systemically and particularly in the lung. The gut-derived SCFAs acetate and propionate enhance DCs, ILC, and macrophage phagocytic function and Tregs balance resulting in the control of lung microbiota and efficient mucocillary clearance of inhaled microbes and particulates. Lung figure adapted from Ref. (41). Abbreviations: CCR9, C-C motif chemokine receptor 9; DCs, dendritic cells; DHA, docosahexaenoic acid; EPA, eicosapentaenoic acid; FAs, fatty acids; GC, goblet cells; GPR, G-protein coupled receptor; ILC, innate lymphoid

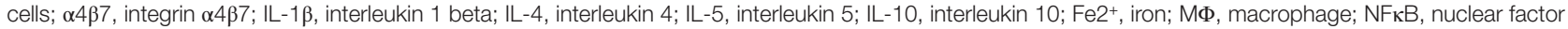
kappa-light-chain-enhancer of activated B cells; PPAR $\gamma$, peroxisome proliferator-activated receptor gamma; RA, retinoic acid; SCFAs, short-chain fatty acids; TGF $\beta$, transforming growth factor beta; Th, T helper; Tregs, T regulatory cells; TLR4, toll-like receptor 4; VitA, vitamin A; VitD, vitamin D; VDR, vitamin D receptor; healthy

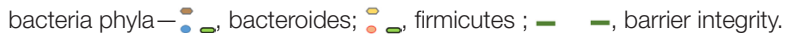

\section{Dairy Products}

Dairy products are a major source of SFA present in our diets. In a Japanese study, an increased incidence of CD was strongly correlated to milk protein (124). Furthermore, an increase in cheese consumption is associated with an increased risk of both UC and CD (125). In line with these findings, IL-10 $10^{-/-}$mice fed a saturated milk fat-derived diet resulted in an increased severity of colitis associated with a colonic Th1 profile and presence of $\mathrm{CD} 4^{+}$ IFN- $\gamma^{+}$cells in the mesenteric lymph nodes (MLNs) as a result of blooming of an opportunistic bacteria Bilophila wadsworthia (126) (Figure 4). Interestingly, WT mice fed milk fat diet and presenting a blooming of $B$. wadsworthia did not develop colitis, indicating the impact of genetic predisposition on the subsequent inflammatory response. Of note, $20 \%$ of patients with UC benefited from excluding milk and cheese from their diet (127). These collected data indicate that dairy products may play a role in IBD pathology. In contrast to IBD, a decreased asthma risk is associated to milk fat $(117,118)$. Additionally, it has been reported children who consumed raw milk during childhood show a reduced risk of developing atopy and/or asthma (128-130). The protective effect of raw milk has been speculated to be due to improvement in nutrition, prevention of lactose intolerance, or the presence of "good" bacteria. However, the topic is still debatable and more studies are needed.

\section{Emulsifiers}

Processed foods have been identified as a risk factor for IBD $(4,115)$ and in 2013 , it was hypothesized that the increased incidence in $\mathrm{CD}$ was the result of a higher consumption of emulsifiers in processed foods (131). Indeed, using an animal model of colitis (IL-10 $0^{-/-}$mice), it was shown that exposure to two common emulsifiers, carboxymethylcellulose (CMC) and polysorbate-80 (P80), aggravated colitis by increasing gut permeability, reducing mucus thickness, promoting higher penetration of intestinal bacteria, and altered microbial composition, particularly by enrichment in Bilophila spp. (Figure 4). Exacerbation in obesity/metabolic syndrome was also observed in emulsifier-treated TLR5 ${ }^{-1-}$ mice (132). Supporting these findings, it was shown in vitro that addition of P80 induced a higher translocation of E. coli across M-cells (133) (Figure 4). 
More recently, using an ex vivo model of human microbiota culture which was exposed to CMC and P80 revealed an altered gene expression and microbial composition by, e.g., induction of bioactive flagellin. However, transfer of emulsifier-treated microbiota to GF mice resulted in a low-grade inflammation and metabolic syndrome features but not colitis (134). The relevance of these findings for the development of the microbiota and immune system and in other chronic conditions is yet to be addressed.

\section{Fibers, Vegetables, Fruits, and Fish}

In contrast to dietary fats, diets rich in fish (n-3 PUFAs), fermentable fibers and vegetables and fruits lower the risk for IBD $(4,115)$. For example, an inverse correlation of eicosapentaenoic acid (EPA) and docosapentaenoic acid with colonic cytokine levels was identified in UC patients (115). Several studies have suggested that a diet low in refined carbohydrates could be beneficial in the treatment of CD, reviewed in Ref. (135); however, clinical trials are needed for this view to be proven $(136,137)$. Findings from a prospective study investigating the long-term intake of dietary fiber and risk of incidence of CD and UC in women revealed a $40 \%$ reduction in risk of developing CD while no association to UC was observed (138). Much of the fiber intake in this study originated from fruits. The Aryl hydrocarbon receptor $(\mathrm{AhR})$ was identified as a potential mechanism linking the positive effects of fruit-derived fiber. AhR is expressed ubiquitously in vertebrate cells and mediates the toxicity of xenobiotic molecules by binding to the AhR nuclear translocator and activating dioxin- or xenobiotic-response element sequences (139). Indole-3-carbinol, a major component of cruciferous vegetables (e.g., broccoli, cabbage, and cauliflower) can activate AhR in the intestine (140), inducing maintenance and expansion of intestinal intraepithelial lymphocytes (IELs) and IL-22-producing ILCs (141). IELs are T cells expressing $\alpha \mathrm{E}$ (CD103)/ $\beta 7$ integrin, localized in between epithelial cells and are characterized as either conventional $\left(\mathrm{CD} 4^{+}\right.$or $\left.\mathrm{CD} 8 \alpha \beta^{+} \mathrm{TCR} \alpha \beta^{+}\right)$or unconventional $\left(\mathrm{TCR} \gamma \delta^{+}\right.$and CD $8 \alpha \alpha^{+} \mathrm{TCR} \alpha \beta^{+}$) IELs. IELs have been regarded as a first line of defense against infected/damaged epithelial cells and are implicated in the regeneration of the intestinal epithelium (142). Indeed, recent studies have demonstrated that IELs play a hitherto underappreciated role in gut epithelial homeostasis (143). In addition, aberrant IEL phenotype and lineages are now evident in pathologies such as celiac disease and enteropathyassociated T lymphoma (144). The roles that these differing IELs play in sensing and interacting with the gut microbiota in IBD and other GI conditions warrants further investigation.

In asthma, a high-fiber intake in late pregnant mothers was correlated with high serum acetate levels and resulted in lower infant GP visits for cough or wheeze (17). In children aged 10-14, a dietary intake of fruits, but not vegetables, was negatively related to wheeze, while no protective effect was identified in adults (27).

Intake of oily fish, such as salmon, sardines, herring, tuna, and mackerel, which are rich in n-3 FAs, have shown a potential benefit in preventing asthma in children and in patients with UC, while no beneficial effect in adults with asthma was reported $(145,146)$.

\section{NUTRIENTS AND THEIR IMPACT ON MICROBIOTA AND IMMUNE RESPONSES AT MUCOSAL SITES}

Recent evidence has identified the existence of a cross talk between the host and the commensal microbiota within the gut. In this dialog, nutrients play an important role either by directly interacting with the host via the epithelium or the intestinal immune system or indirectly, by modulating the composition of the commensal microbiota which in turn will interact with the immune system, and vice versa (Figure $\mathbf{2 A}$ ). The immune system will react promptly and adapt depending on the microbiota (commensal, pathobionts, and pathogens) and the diet (prebiotics, supplements, or detrimental nutrients). The worldwide increased incidence of IBD and asthma has been hypothesized to be associated with changes in dietary habits, i.e., westernized life style. In the following sections, we will outline several important macro- and micronutrients associated with diets and their effect on immune responses at mucosal sites important in health and in IBD and asthma.

\section{Macronutrients}

In this section, we will summarize the impact of the main macronutrients fat, carbohydrates and proteins on immune responses and microbiota (Table 1).

\section{Fats}

Under this section, we will outline the impact that saturated-, monounsaturated-, and PUFAs have on immune and microbial responses associated with IBD and asthma.

\section{Saturated Fatty Acids}

Fatty acids belonging to SFAs and containing 12 or less carbon $(\mathrm{CX})$ atoms, include carprylic acid (C8:0), capric acid (C10:0), and lauric acid (C12:0), are found in vegetable oils, cocoa butter, palm oil. SFAs containing more than 12 carbon atoms include myristic (C14:0), palmitic acid (C16:0), stearic acid (C18:0) which can be found in lard, butter, beef, pork, chicken fats, eggs, and vegetable oils (147).

Evidence exists that SFA can act as pro-inflammatory mediators, e.g., as ligands for TLR4 $(148,149)$. Potential mechanisms by which SFAs elicit a TLR4-induced inflammatory response have been recently reviewed (12). Briefly, it is proposed that similar to lipopolysaccharide (LPS), the SFA lauric acid can trigger TLR4 via CD14/MD2 activation thereby promoting the expression of the transcription factor NF- $\kappa B$, which plays a crucial role in the induction of the pro-inflammatory mediators COX2, TNF $\alpha$, IL-1 $\beta$, IL-6, CXCL8, IL-12, and IFN $\gamma$ (150) (Figure 4). Comparably, palmitic acid and stearate can induce pro-inflammatory cytokine production from macrophages via degranulation of Ikappa B alpha $(\mathrm{I} \kappa \mathrm{B} \alpha)$ and phosphorylation of c-Jun N-terminal kinases, MAPKs, and extracellular signal-regulated kinases (ERK). LPS together with palmitate activate reactive oxygen species and the NLRP3 inflammasome leading to IL-1 $\beta$ maturation in macrophages (95) (Figure 4). Moreover, a high intake of SFA, i.e., given in western diet, leads to the modification of the gut microbiota raising the proportion of Gram-negative bacteria and thereby the natural ligand for TLR4, LPS, as well as 


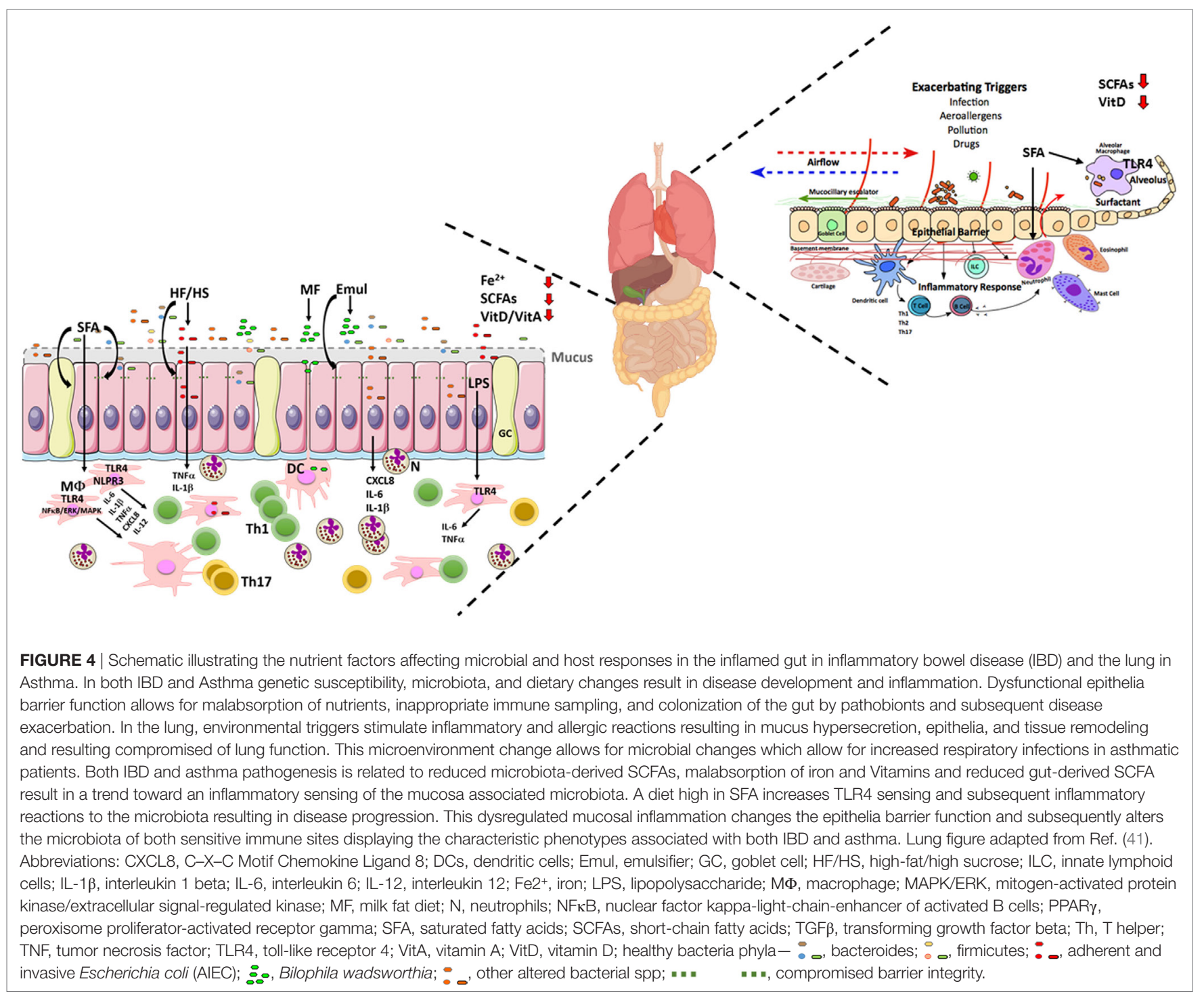

an increase in intestinal permeability, which in itself induces a state of metabolic endotoxemia (151) (Figure 4). Intake of SFAs can also increase plasma low-density lipoprotein cholesterol by inducing the formation of low-density Lipoprotein (LDL) and by reducing LDL turn-over leading to the generation of oxidized LDL (152). Both oxidized LDL and phospholipids are damageassociated molecular patterns, which are also recognized by TLR4 and can trigger a CD36-TLR4-TLR6-mediated inflammatory response (153). These findings support a pro-inflammatory effect of SFA on the microbiota on innate responses in macrophages.

To date, mechanistic studies on saturated fats in human IBD are scarce and, therefore, much of our knowledge on SFAs and intestinal inflammation emanates from studies in experimental models. TNF $\triangle \mathrm{ARE}$ mice fed a palm oil-based high-fat diet for up to 12 weeks resulted in an initial acceleration of ileitis followed by worsening of proximal colitis associated with loss of $\mathrm{TJ}$ protein occludin in the distal ileum, endotoxin translocation, and increased infiltration of DCs and Th17 cells into the lamina propria but without the development of obesity or obesityassociated metabolic features (154). Similarly, $\mathrm{Mdrla}^{-/-}$mice fed a lard-based high-fat diet for 12 weeks led to an exacerbation of spontaneous colitis associated with elongated crypts, loss of goblet cells, and infiltration of immune cells. Contrary to TNF $\Delta$ ARE mice, Mdr1a ${ }^{-/-}$mice developed obesity as characterized by increased adiposity and presence of foamy macrophages, while WT mice did not (155). Rats fed a diet containing capric and lauric acid followed by DSS-induced colitis, developed worse colitis associated with a higher colonic myeloperoxidase activity and a pro-inflammatory cytokine profile as well as a reduction in goblet cells (156). Overall, these findings indicate that the type of SFA diet, microbiota status, diet regimen, and/or the genetic background of the animals determine the development of intestinal inflammation and obesity, suggesting that different dietary-induced mechanisms regulate these two conditions. In asthma, SFA have been shown to effect symptoms and immune activation, e.g., by inducing a neutrophilic inflammation and 
suppressing bronchodilator recovery in asthmatic patients (11, 27) (Figure 4).

\section{Monounsaturated Fatty Acids and Derived Oils}

Monounsaturated fatty acids, including palmitoleic acid (C16:1) and oleic acid (C18:1, OA) are normally found in macadamia nuts, blue-green algae, olive oil, canola oil, beef tallow, lard, and avocado.

Diets rich in MUFA appear to reduce LDL cholesterol and potentially increase high-density lipoprotein (HDL) cholesterol (157), and palmitoleate treatment of M1 macrophages induce an anti-inflammatory M2 profile (158) indicating an anti-inflammatory capacity of MUFAs. The specific role of MUFAs in IBD and asthma remains inconclusive. For example, a prospective study by de Silva and colleagues showed that a dietary oleic acid was inversely associated with UC development (114), while palmitoleic and oleic acid treatment of polarized intestinal epithelial cells impaired epithelial barrier function (159). MUFA and oleic acid intake indicated an increased risk of wheeze and non-atopic asthma, respectively (160). Extra virgin olive oil, high in MUFAs, contains highly bioactive components which are present in the unsaponifiable fraction (UF). Beneficial effects of UF and olive oil were demonstrated in an acuteDSS model of colitis and in mice with C. rodentium induced colitis. Disease amelioration included alleviation of oxidative stress, reduction of pro-inflammatory proteins and increased levels of intestinal alkaline phosphatase, which can de-phosphorylate bacterial LPS (161-163). In line with these findings, isolated blood and intestinal $\mathrm{T}$ cells from UC patients treated with UF resulted in a reduction in $\mathrm{T}$ cell activation, $\beta 7$ integrin expression and IFN $\gamma$ production as well as induction of apoptosis (164). Findings from these studies indicate MUFA exert both pro- and anti-inflammatory activities in these mucosal conditions.

\section{Polyunsaturated Fatty Acids}

Polyunsaturated fatty acids are FAs containing more than one double carbon bonds. Therefore, naturally, they are more prone to oxidation and oxidized LDL synthesis. Long chain PUFAs are divided in two main groups; omega-3 (n-3) PUFAs including-alpha-linolenic acid (ALA, C18:2), docosahexaenoic acid (DHA, C22:6), and EPA (C20:5); and omega-6 (n-6) PUFAs including - linoleic acid (LA, C18:3), and arachidonic acid (ARA, 20:4). LA and ALA are referred to as essential FAs as they are the precursors of ARA, EPA, and DHA. DHA and EPA compete for the enzymes and products of ARA metabolism whereby they can antagonize the formation of inflammation related eicosanoid mediators $(165,166)$.

Arachidonic acid is the primary n-6 PUFA found in inflammatory cells and is important for the production of inflammatory eicosanoids. ARA is formed out of LA which is further converted to prostaglandins [e.g., prostaglandin $\mathrm{E}_{2}\left(\mathrm{PGE}_{2}\right)$, leukotrienes $\left(\mathrm{LTBD}_{4}\right)$, and other lipoxygenase or cyclooxygenase products (COX1/-2)], the so-called eicosanoids, all of which have pro- and anti-inflammatory in addition to atherogenic and pro-thrombotic effects (166). $\mathrm{PGE}_{2}$ is one of the key prostaglandins produced in the intestine where it has dual functions: (1) a pro-inflammatory role, e.g., it is produced by macrophages and neutrophils as a response to inflammatory stimuli and (2) a regulatory role, by inducing immune tolerance, independent of IL-10 or Tregs (167).

n-3 PUFAs are primarily sourced from the human diet, with DHA and EPA especially sourced from fish (e.g., salmon) and ALA from seed oils (e.g., walnut, linseed oil). Several reports have highlighted their effect in preventing and/or treatment of different inflammatory diseases in animals and humans, including IBD and asthma. n-3 PUFAs can inhibit TLR4 signaling and the subsequent gene transcription of pro-inflammatory mediators (168), a process partly mediated via GPR120 (169) (Figure 3). n-3 PUFAs can also activate the anti-inflammatory transcription factor PPAR- $\gamma$ and inhibit NF- $\kappa$ B (Figure 3) and the subsequent pro-inflammatory cytokine production including TNF $\alpha$, activity which is highly expressed in the mucosa of patients with IBD and asthma subtypes (13, 170, 171). DHA can also improve epithelial barrier integrity by increasing the expression of the TJ proteins occludin and claudin-1 (Figure 3) (172), as the integrity of the epithelium is critical in preventing paracellular translocation of LPS into systemic circulation. PUFA supplementation in particular those related to fish oils can also modulate asthma symptoms $(173,174)$, with reduction of wheeze, improved pulmonary function and reduced pro-inflammatory mediators in sputum. However, it should be noted that many trials are designed to measure different outcomes which can deliver conflicting findings $(27,175)$. With the evolution in food technology and modern agriculture in the last 100 years the amount of n-6 FAs, e.g., LA present in our food has increased due to change in animal feed from grass to grains $(176,177)$. Therefore, the ratio of n-6/n-3 PUFAs present in the food has changed from 1:1 to 16:1 in USA/Europe (177) (Figure 2). This ratio has increased dramatically due to food processing, less fish and fiber consumption, and the dietary habits of farm animals. In line with this, a recent study identified a higher ARA:EPA ratio in the inflamed mucosa of UC patients, which correlated with the severity of the disease (178). No association of $n-6 / n-3$ ratio was found in individuals with hay fever or allergic sensitization (179). The relevance of a lack of $n-6 / n-3$ ratio association to asthma is still to be uncovered.

\section{Carbohydrates}

Carbohydrates are divided into four groups: monosaccharides, disaccharides, oligosaccharides and polysaccharides. Generally, monosaccharides and disaccharides are referred to as sugar. In the western diet a large amount of calories are ingested in form of refined carbohydrates, i.e., sucrose, starch, fructose syrup, etc.-obtained from soft drinks, pastries and desserts, and white bread. This energy-dense but nutrient-poor diet is a risk factor for obesity, type 2 diabetes, cardiovascular diseases and more. Therefore, the biological plausibility exists that it has impact on intestinal inflammation and asthma. Moreover, related to the carbohydrates that can be metabolically used by gut microbes, the term "microbiota-accessible carbohydrate" has been proposed. The term refers to the ability of microbial carbohydrates to modify the composition of the microbiota, and dictate the functionality and metabolic output (180). 


\section{Fibers}

Dietary fiber is a plant-based nutrient and a type of carbohydrate, which due to its biochemical structures resists digestion by intestinal and pancreatic enzymes in the human GI tract. Therefore, the fiber passes through the GI tract relatively intact. Fermentable carbohydrate substrates such as non-starch polysaccharides, resistant starch and oligosaccharides serve as important substrates for the gut microbiota. The microbes located in the human colon use fermentation to produce SCFAs, lactate and gas (181). These fermentation products selectively promote the growth of beneficial Bifidobacteria and Lactobacilli and exert anti-inflammatory (inhibition of NFKB transcription via GPR41) and anti-carcinogenic functions (182).

Short-Chain Fatty Acids. Upon fermentation of dietary fiber, bacterial metabolites such as SCFAs are produced in the colon. SCFA mediates the communication between the commensal microbiota and the immune system affecting the balance between pro- and anti-inflammatory responses. The beneficial effects of butyrate on colonic health are particularly well established (183). Microbial-derived butyrate and to a lesser extent acetate and propionate, can facilitate the generation of extrathymic Foxp $3^{+}$ Tregs which are crucial for limiting intestinal inflammation $(17,184,185)$ (Figure 3). Presence of butyrate during human DC maturation results in a tolerogenic phenotype, with an increased expression of IL-10 $(186,187)$, further supporting the regulatory potential of SCFAs (Figure 3). SCFA can signal through the activation of specific G-protein coupled receptors (GPCRs), GPR41, GPR43, GPR109, which are particularly expressed in immune cells, e.g., polymorphonuclear leukocytes, and are suggested to participate in immune surveillance of the colonic mucosa affecting the balance between pro- and anti-inflammatory responses (188). GPR43 is additionally expressed in the colonic epithelium where it can mediate SCFA-regulated effects on epithelial barrier and proliferation (Figure 3). Butyrate is also a natural ligand for PPAR $\gamma$, which is expressed in colonic epithelial cells, macrophages and lymphocytes. Colonic PPAR $\gamma$ expression is linked to host-microbe interactions with natural (e.g., SCFAbutyrate, conjugated LA) and synthetic (e.g., 5-aminosalicylic acid) PPAR $\gamma$ ligands preventing inflammation in experimental colitis (189).

A significant decrease in the number of butyrate-producing bacteria including Eubacterium rectale/Roseburia spp (which belong to Clostridium coccoides) and F. prausnitzii (which belong to Clostridium leptum cluster), both within the Firmicutes phylum was revealed in patients with UC and CD $(190,191)$. In patients with UC, colonic irrigation with butyrate is able to limit inflammation and in experimental models it ameliorates inflammation and modifies microbial composition $(183,192)$.

In the Canadian CHILD study the SCFA acetate was reduced in the feces of infants with atopy and wheeze (83). Feeding a high fiber diet to mice has resulted in gut microbiota alteration which concomitantly leads to increased serum SCFAs, such as acetate and propionate, and alleviates allergic asthma symptoms (Figure 3). These SCFAs induced an enhanced DC and macrophage phagocytosis and reduced Th2 responses in the murine lung $(17,23,193)$. Furthermore, binding of propionate to GPR41 and acetate and propionate to GPR43 also supported the reduction in airway inflammation $(17,23,194,195)$. These microbiotamediated effects are also linked to maternal influences of asthma risk, where high serum acetate concentrations, but not propionate, in pregnant mothers' correlate with reduced asthma risk and are thought to modulate Tregs biology of the fetus (17). These findings clearly point to a crosstalk between the gut and the lung via SCFA in asthma and between the microbiota and the intestine in IBD, indicating that treatments aiming to increase SCFAs and SCFA producing bacteria should be further investigated.

\section{Proteins}

Proteins consist of carbon, hydrogen, oxygen, and nitrogen elements. They are essential nutrients and are involved in virtually all physiological functions. High protein intake, especially animal derived protein, is associated with an increased risk of CD (196). In asthmatics high ingestion of cured meats is linked with worsening of symptoms (24).

Carnitine is an amino acid derivative synthesized primarily in the liver and kidneys from lysine and methionine and is involved in lipid metabolism in eukaryotic cells (197). In humans, the main source of carnitine is red meat. Humans with an omnivorous diet following ingestion of L-carnitine, presented increased plasma trimethylamine-N-oxide (TMAO) levels, which was dependent on microbiota mechanisms, when compared to vegans or vegetarians. Elevated plasma levels of TMAO are positively correlated with an increased risk for major adverse cardiovascular events (198). However, TMAO has also protective functions, e.g., by protecting cells from osmotic and hydrostatic damage, and therefore, is essential for all organisms (25). A recent study proposed plasma TMAO as a non-invasive biomarker for IBD, as decreased TMAO levels are seen in these patients (199). The reduced TMAO was likely related to alterations in the gut microbiome (the abundance of anaerobes or facultative anaerobes) in these patients. TMAO is also an oxidation product of trimethylamine which can be found in seafood, fish, etc. Consumption of TMAO-containing food, e.g., oily fish can lead to accumulation of TMAO and protection against asthma in childhood (200). Further studies are necessary to shed a light into mechanisms that underlie the association of high intake of animal protein in these conditions.

Other studies have also shown how dietary peptides and amino acids can modulate intestinal immune functions and influence inflammatory responses. Supplementation with the dipeptide alanine-glutamine, led to decreased expression of inflammatory mediators and increased expression of mucin 2 (MUC2) promoting mucosal recovery in the DSS-induced colitis mouse model (26). Moreover, lower serum tryptophan is associated to active CD (201). Supplementing tryptophan presented beneficial effects in the DSS-induced porcine IBD model, by inducing T cell apoptosis and thereby inhibiting Th1-mediated immune responses and subsequently reducing inflammation (202).

\section{Micronutrients}

Micronutrients or trace elements are nutrients required by organisms in small quantities to maintain a variety of physiological functions and as most of them are essential, they need 
to be obtained from the diet. These minerals include iron, cobalt, chromium, copper, iodine, manganese, selenium (Se), zinc ( $\mathrm{Zn})$ and vitamins include Vitamin A (VitA), vitamin B1 (VitB1), Vitamin B6 (VitB6), Vitamin B9 (VitB9), VitB12, VitD, and VitK. Micronutrient deficiencies impair immune function and increase the severity of disease (203). Micronutrient deficiencies occur in more than half of patients with IBD, with CD patients presenting more deficiencies than UC patients, with the most common being VitB1, VitB6, VitB12, VitD, VitK, iron, folic acid, Se, and Zn (204). This deficiency in vitamins (hypovitaminosis) is thought to be the result of malabsorption, altered microbial composition and impaired host mucosal system. Low dietary intakes of VitA and VitC are associated with asthmatics (205). The next section summarizes the most relevant micronutrients in relation to IBD and asthma pathology.

\section{Vitamins}

Vitamins can be absorbed from the diet but the gut commensal microbiota play an important role in their production and bioavailability (206). Indeed, the diet of germ-free mice requires supplementation with dietary VitK and B Vitamins to maintain a normal function (207).

\section{Vitamin A}

Vitamin A is a group of unsaturated organic compounds including retinol, retinoic acid (RA), and several pro-vitamin A carotenoids including beta-carotene. They are fat-soluble substances obtained from animal food sources. RA is a metabolite of VitA, which is produced by $\mathrm{CD}_{103}{ }^{+} \mathrm{DCs}$ and epithelial cells and acts as ligand for RA receptors (RARs) and Retinoic-XReceptor (RXR), transcription factors regulating gene expression. Lymphoid cells express RAR, RXRs and RA, which are known to regulate IgA and mucosal homeostasis (Figure 3). DCs from Gut associated lymphoid tissue (GALT) produce RA to sustain gut tropism and in synergy with GALT-DC-derived IL-6 or IL-5, induce IgA production (208) (Figure 3). RA can also control the presence of ROR $\gamma^{+}$ILCs, the formation of lymphoid tissue in the small intestine (209) and appears to be a cofactor in IgA class switch recombination (210). RA can also induce the gut-homing capacity on T cells by the up-regulation of the integrin $\alpha 4 \beta 7$ and the chemokine receptor CCR9 (211) (Figure 3). A diet deficient in VitA can lead to a systemic proinflammatory state, due to a lack of homing integrins in MLN activated T- and B-cells, which then go into systemic circulation instead of migrating back to the gut $(212,213)$. RA, together with TGF $\beta$, promotes naïve $\mathrm{CD} 4^{+}$to become Foxp $3^{+}$Tregs and RA alone has also inhibitory effects on Th17 cell differentiation (Figure 3). Others have also described that VitA can impair the reprogramming of Tregs into IL-17-producing cells during intestinal inflammation (214).

Patients with IBD have been reported to be deficient in VitA (Figure 4). Cytochrome P450 26 B1 (CYP26B1) participates in the degradation of RA, and homozygous carriers of the CYP26B1 polymorphism rs2241057 have been associated as risk factor of CD development, linking an elevated catabolic function of RA to IBD (215). Supplementation of VitA/RA seems to attenuate intestinal inflammation in experimental models and even induces a shift in Th17/Tregs in UC biopsies (216-218). VitA appears to influence the microbiota, as its deficiency seems to favor a nonsymptomatic reservoir of $E$. coli-like enteric infections $(219,220)$.

\section{Vitamin D}

Vitamin D belongs to a group of fat-soluble vitamins which are essential for bone mineralization and optimal intestinal absorption of calcium, iron, magnesium, phosphate, and Zn. VitD regulates the epithelial integrity/barrier function and is involved in the detoxification and protection against infection as well as in controlling of the commensal microbiota $(221,222)$.

Vitamin D can be obtained from the diet or by dermal synthesis, e.g., in the skin where it is produced from 7-dehydrocholesterol (222). 1,25-dihydroxyvitamin D3 [1,25(OH)2D3] is the active form, which arises from the bloodstream (endocrine action) or it can be locally produced from circulating $25(\mathrm{OH}) \mathrm{D} 3$ within intestinal cells (intracrine, autocrine and paracrine action). VitD is ubiquitously expressed in several human tissues including immune cells, but its expression is higher in intestinal epithelial cells (223). VitD deficiency has been associated with a greater disease activity and extended disease duration in patients with IBD (Figure 4) - why a supplementation of VitD is often required. Human polymorphisms in the vitamin $\mathrm{D}$ receptor (VDR) are also associated with susceptibility to IBD (224). Vitamin D3 has been linked to beneficial effects in asthma; however, the benefits are mainly observed in children or via maternal supplementation (225). Recent studies have identified that VitD3 appear to modify VEGF function and reduction in airway smooth muscle proliferation (226).

The biological actions of $1,25(\mathrm{OH}) 2 \mathrm{D} 3$ are mediated via the VDR, which acts as an heterodimer with RXR to activate VitD target genes $(222,227)$. VDR targeted pathways regulating inflammatory responses include TLR and NF-кB signaling, Th17/Tregs response, apoptosis, cell proliferation and differentiation, barrier function, etc. (Figure 3). The antiinflammatory role of $1,25(\mathrm{OH}) 2 \mathrm{D} 3$ is based on the suppressive

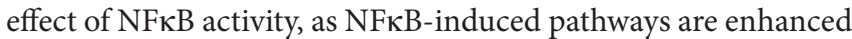
in $\mathrm{VDR}^{-/-}$mice exposed to bacterial and chemically induced colitis (228). 1,25(OH)2D3 regulates intestinal barrier trough the up-regulation of TJ proteins including occludin, ZO1, claudin 2 and E-cadherin $(221,229)$ (Figure 3). In support of this, IL-10-1- mice expressing the human VDR in intestinal epithelial cells resulted in a reduced development of spontaneous colitis (230). VitD has been linked to the modulation and control of the gut commensal microbial composition (Figure 3), since $\mathrm{VDR}^{-/-}$mice present an altered microbiota with more abundance on Bacteroidetes and Proteobacteria phyla and less abundance on the Firmicutes phyla (231). Interestingly, analysis of mice treated with $1,25(\mathrm{OH}) 2 \mathrm{D} 3$ revealed an increased $C$. rodentium load in the colon and spleen doubtless due to the suppression of a Th17 response, which is essential for C. rodentium clearance (232). In contrast, following infection with $C$. rodentium, a diet deficient in VitD aggravated barrier function, microbiota composition and inflammation (233). Correspondingly, mice fed a high-fat and VitD deficient diet presented increased ileal antimicrobial peptides and Helicobacter hepaticus and reductions in TJ proteins, MUC2 expression and abundance of beneficial bacteria such as 
TABLE 1 | Dietary factors and host inflammatory responses at mucosal sites.

\begin{tabular}{|c|c|c|c|}
\hline \multirow[t]{2}{*}{ Dietary factor } & \multicolumn{2}{|c|}{ Inflammatory/immune response } & \multirow[t]{2}{*}{ Reference } \\
\hline & Intestine & Lung & \\
\hline \multicolumn{4}{|l|}{ Macronutrients } \\
\hline \multicolumn{4}{|l|}{ Fat } \\
\hline \multirow[t]{2}{*}{ High-fat diet } & \multirow[t]{2}{*}{ Permeability of epithelial barrier $\uparrow$} & Neutrophil $\uparrow$ & \multirow[t]{2}{*}{$(10,11)$} \\
\hline & & TLR4 mRNA $\uparrow$ & \\
\hline Saturated fatty acids & Activation of TLR4 $\uparrow$ & & $(12)$ \\
\hline \multirow[t]{5}{*}{ n-3 PUFA, e.g., EPA, DHA } & PG (series-3) $\uparrow$ & Maternal supplementation reduced Childhood & \multirow{5}{*}{$\begin{array}{c}(13) \\
(14,15)\end{array}$} \\
\hline & LK (series-5) $\uparrow$ & Asthma & \\
\hline & Leukocyte chemotaxis $\downarrow$ & IL-13 cord blood $\downarrow$ & \\
\hline & $\|-1 \beta \downarrow, \mathrm{TNF} \alpha \downarrow$ & Mucus (murine) $\downarrow$ & \\
\hline & Resolvins, Maresins and Protectins $\uparrow$ & CD45+ inflammatory cell infiltrates (murine) $\downarrow$ & \\
\hline \multirow[t]{2}{*}{ n-6 PUFA, e.g., ARA, linoleic acid } & PG (series-2) $\uparrow$ & Mucus (murine) $\downarrow$ & \multirow[t]{2}{*}{$(14)$} \\
\hline & LK (series-4) $\uparrow$ & & \\
\hline \multirow[t]{3}{*}{ SCFA, e.g., butyrate } & Energy source for colonocytes & Allergy $\downarrow$ & \multirow[t]{3}{*}{$(16,17)$} \\
\hline & Barrier function $\uparrow$ & & \\
\hline & Peroxisome proliferator-activated receptor $\gamma$ activation $\uparrow$ & & \\
\hline \multicolumn{4}{|l|}{ Carbohydrates } \\
\hline Sucrose & Permeability of epithelial barrier $\uparrow$ & Asthma and dental caries $\uparrow$ & $(18-21)$ \\
\hline \multirow[t]{3}{*}{ Fermentable carbohydrates, e.g., fiber } & \multirow[t]{3}{*}{ Butyrate production $\uparrow$} & SCFA levels $\uparrow$ & \multirow[t]{3}{*}{$(22,23)$} \\
\hline & & DC maturation $\downarrow$ & \\
\hline & & $\mathrm{T}_{\mathrm{H}} 2$ response $\downarrow$ & \\
\hline
\end{tabular}

\begin{tabular}{|c|c|c|c|}
\hline \multicolumn{4}{|l|}{ Proteins } \\
\hline Animal-derived proteins, e.g., carnitine & TMAO synthesis $\uparrow$ & Asthma exacerbation (cured meats) & $(24,25)$ \\
\hline Dipeptides, e.g., alanine-glutamine & Mucin 2 expression $\uparrow$ & & (26) \\
\hline \multicolumn{4}{|l|}{ Micronutrients } \\
\hline \multicolumn{4}{|l|}{ Vitamins } \\
\hline Vitamin A, e.g., RA, $\beta$-carrotene & Induction of tolerogenic DC and Tregs $\uparrow$ & & $(27,28)$ \\
\hline Vitamin D & $\begin{array}{l}\text { Cathelicidin production } \\
\text { Innate defense toward regulatory state } \uparrow \\
\mathrm{Ca}^{2+} \text { absorption } \uparrow\end{array}$ & $\begin{array}{l}\text { Maternal supplementation reduction in airway } \\
\text { smooth muscle }\end{array}$ & $(27,29,30)$ \\
\hline $\begin{array}{l}\text { Vitamin B, e.g., thiamine, folate, } \\
\text { cobalamine, pyridoxine }\end{array}$ & Vitamin B9 deficiency - colonic Foxp3 + Tregs $\downarrow$ & Folate deficiency - asthma exacerbations & $(31-34)$ \\
\hline \multicolumn{4}{|l|}{ Minerals } \\
\hline Iron & $\begin{array}{l}\text { Incorporated into iron-sulfur clusters, redox cofactors, or used } \\
\text { metalloenzymes }\end{array}$ & & $(35,36)$ \\
\hline
\end{tabular}

ARA, arachidonic acid; $\mathrm{Ca}^{2+}$, calcium; DHA, docosahexaenoic acid; EPA, eicosapentaenoic acid; Foxp3, Forkhead-Box-Protein P3; LK, leukotrienes; PG, prostaglandins; RA, retinoic acid; TLR4, toll-like receptor 4; PUFA, polyunsaturated fatty acid; SCFA, short-chain fatty acid; Tregs, T regulatory cells; CD, cluster of differentiation; DC, dendritic cells;

IL, interleukin; TMAO, trimethylamine- $N$-oxide; Th, Thelper cell.

Akkermansia muciniphila developing insulin resistance and fatty liver (234).

\section{Other Vitamins}

Vitamin B1. Vitamin B1, also known as thiamine, is mainly obtained from whole grains, trout, pork, peas and beans. It has an important role in the catabolism of sugars and amino acids $(235,236)$. Thiamine is a component of the pyruvate dehydrogenase that catalyzes the formation of Acetyl CoA in FA synthesis, a pathway which is altered in IBD (237). Pediatric IBD patients presented alterations in cellular transport of thiamine and FAs synthesis (e.g., bile acids) $(237,238)$. Altogether, these findings highlight a potential link between the microbiota, glucose, FAs and mucosal alteration leading to intestinal inflammation in which thiamine may have a key role.

Vitamin B6. Vitamin B6 is a water-soluble vitamin, also known as pyridoxine, which exists in several forms and can be obtained from fruits, vegetables, grains, fish and meat. The biologically active form of VitB6, Pyridoxal 5'-phosphate (PLP), is involved in the synthesis or metabolism of proteins, lipids and carbohydrates and important in the modulation of immune pathways $(236,239)$. PLP treatment ameliorated colitis in IL- $10^{-/-}$mice due to a reduction in colonic TNF $\alpha, \mathrm{IL}-6, \mathrm{IFN} \gamma, \mathrm{COX}-2$ and nitric oxide 
synthase (iNOS) expression and modulation of the chemotactic lipid S1P (240). Eubacterium rectale, a dominant non-pathogenic fecal Gram-positive commensal bacterium has been described as one of the important bacterial group synthetizing PLP (241).

Vitamin B9. Vitamin B9 is a water-soluble vitamin also known as folic acid or folate, it can be obtained from vegetables and fruits and is important in DNA repair and methylation aiding rapid cell division and growth during, e.g., infancy and pregnancy. Bacteria linked to folate biosynthesis include Bifidobacteria and Lactobacilli groups $(207,242,243)$. A deficiency in VitB9 has been more commonly ascribed to CD, especially in patients with ileal disease, than in UC patients $(244,245)$. VitB9 deficiency has also been associated with a reduction in colonic Foxp $3^{+}$Tregs (33). Folate supplementation during pregnancy has been linked to an increased risk of infants developing asthma; however, this is controversial with conflicting studies providing little clear evidence $(34,246)$.

Vitamin $K$. Vitamin $\mathrm{K}$ is a fat-soluble vitamin required for synthesis of certain proteins involved in blood coagulation and is linked to calcium pathways and calcification. VitK1 can be obtained from, e.g., meats, cheeses, and eggs or synthetized (VitK2) by the microbiota of the colon de novo or from VitK1 $(236,247,248)$. VitK deficiency has been associated with both adult and pediatric CD patients (249). A protective role of VitK was shown in a model of DSS-induced colitis associated with a reduction in IL-6 production from B cells (250).

\section{Minerals}

Minerals are obtained from the diet, and are essential nutrients needed by organisms for synthesis of common organic molecules. Accordingly, mineral deficiencies in the westernized diet have a major impact on host health. The next section summarizes the most relevant minerals in relation to IBD and asthma pathology.

\section{Iron}

Anemia is one of the most common extra-intestinal manifestations of IBD. The deficiency, results from either an absolute state, i.e., poor dietary intake of iron, reduced iron absorption, and/ or increased blood loss from chronically inflamed intestinal mucosa; and/or functional iron state, i.e., deficiency in VitB12 and insufficient availability of iron for incorporation into erythroid precursors despite normal or increased body iron stores $(251,252)$. It is estimated that up to $80 \%$ of patients with IBD present with anemia (253). Consequently, oral or i.v. iron supplementation is important in treatment of IBD patients. Nonetheless, caution is needed as non-absorbed iron can be toxic to intestinal epithelial cells, since it can stimulate growth and virulence of bacteria and appears to worsen disease activity in the patients $(178,254)$. In support of this data, rats supplemented with iron and exposed to DSS-induced colitis revealed an increased neutrophil infiltration, TNF $\alpha$ and IL-1 expression and NF- $\kappa \mathrm{B}$ activation - all of which could be prevented by supplementing the diet with VitE (DL-alpha-tocopherol acetate) (255). In contrast, rats with humanized gut microbiota and fed dietary iron supplementation exhibited an increased abundance of Bacteroides spp. and Clostridium cluster IV, leading to an increased butyrate concentration in the gut, without the induction of colitis. Thus, iron supplementation can increase the proportion of beneficial gut microbiota metabolites which may contribute to gut health in IBD individuals (256).

\section{Other Minerals}

Selenium. Selenium is an essential antioxidant trace mineral which can be obtained from proteins or vegetables and is used in the body to synthetize the amino acid selenocysteine (selenoproteins). Large amounts of Se can cause toxicity (257). The amino acid transporters SLC3A1 and SLC1A4 have been suggested as Se transporters (236) and play a role in intestinal epithelial permeability and barrier function. Lower Se serum levels have been described in children with IBD (258). A possible therapeutic role for Se has been described, whereby macrophage derived selenoproteins enhance 15-hydroxyprostaglandine dehydrogenase (15-PGDH) and protects mice from DSS-induced colitis (259). A potential role for Se in asthma pathogenesis has been hypothesized; however, data from human studies are conflicting. A benefit of Se supplementation in animal asthma studies has been identified by regulating Th cell differentiation (260).

Zinc. Zinc is an important mineral involved in wound repair, tissue regeneration, and the immune response. Low serum $\mathrm{Zn}$ levels have been reported in children with IBD (258). $\mathrm{Zn}$ given orally to CD patients restored intestinal permeability by modulating TJ proteins in both the small intestine and colon (261). Zn concentrations have been found to be significantly lower in asthmatic patients and it is thought to result in reduced antioxidant function increasing asthma risk (262).

\section{CONCLUSION AND FUTURE PERSPECTIVES}

The increasing incidence of IBD and asthma implies a fundamental role for environmental factors. Several lines of evidence have identified the consumption of a diet high in saturated fat and high in sucrose increases a person's risk for several chronic conditions including IBD and asthma $(4,27)$. Studies in animal models, human cells and tissues for both conditions have also highlighted the complex interaction between diet, the microbiota and the host response, especially regarding aggravation of inflammatory responses upon consumption of certain triggering nutrients and diets. Dietary ingredients in the western diet are not limited to the ones listed in this review. Apart from the increased consumption of saturated fats and sucrose, there is an increased consumption of food additives including sweeteners, emulsifiers, thickeners, preservatives and food colorings. Some of these have already been associated to asthma and IBD (122, $132,134)$ but there is a need for larger epidemiological studies to identify the effect that these products may have on both microbial composition and host responses (e.g., inflammation, metabolism, etc.) in disease development. In an elegant study by Arrieta and colleagues it was shown that changes in the microbiota especially at a young age, can help to identify a window of 
opportunity for bacteria colonization and an appropriate immune education in asthmatics (83). Future studies aiming to identify whether a similar new widow also exists prior to IBD onset and whether the education of the mucosal immune system can be regulated by specific diet combinations and corresponding microbial alterations are required. Such studies would likely lead to the discovery of new target/regulatory mechanisms for both conditions.

Individuals with IBD and asthma present with a deficiency in certain essential nutrients, e.g., VitD and Iron. The reductionist approach undertaken whereby the effect of one single nutrient has been investigated in animal models, has so far provided major insights into the regulatory mechanisms associated with inflammation and metabolism. In addition, the majority of animal studies and diets, employs standard "high fat" diet containing a nutrient content designed to sustain rodent health and are, therefore, not relevant to a human and patient dietary intake (263). Studies using more complex systems, e.g., humanized mice (consisting of both a human immune system and human microbiota) fed with a humanized diet will provide a deeper mechanistic understanding of the complex diet-microbiota-host network. Integration of various approaches, e.g., genomic, transcriptomic,

\section{REFERENCES}

1. El-Gabalawy H, Guenther LC, Bernstein CN. Epidemiology of immune-mediated inflammatory diseases: incidence, prevalence, natural history, and comorbidities.J RheumatolSuppl(2010) 85:2-10. doi:10.3899/jrheum.091461

2. Molodecky NA I, Soon S, Rabi DM, Ghali WA, Ferris M, Chernoff G, et al. Increasing incidence and prevalence of the inflammatory bowel diseases with time, based on systematic review. Gastroenterology (2012) 142:46-54. e42; quiz e30. doi:10.1053/j.gastro.2011.10.001

3. Kotlyar DS, Shum M, Hsieh J, Blonski W, Greenwald DA. Non-pulmonary allergic diseases and inflammatory bowel disease: a qualitative review. World J Gastroenterol (2014) 20:11023-32. doi:10.3748/wjg.v20.i32.11023

4. Uranga JA, Lopez-Miranda V, Lombo F, Abalo R. Food, nutrients and nutraceuticals affecting the course of inflammatory bowel disease. Pharmacol Rep (2016) 68:816-26. doi:10.1016/j.pharep.2016.05.002

5. Leiria LO, Martins MA, Saad MJ. Obesity and asthma: beyond T(H)2 inflammation. Metabolism (2015) 64:172-81. doi:10.1016/j.metabol.2014.10.002

6. Park Y, Subar AF, Hollenbeck A, Schatzkin A. Dietary fiber intake and mortality in the NIH-AARP diet and health study. Arch Intern Med (2011) 171:1061-8. doi:10.1001/archinternmed.2011.18

7. Tilg H, Moschen AR. Food, immunity, and the microbiome. Gastroenterology (2015) 148:1107-19. doi:10.1053/j.gastro.2014.12.036

8. Mozaffarian D, Hao T, Rimm EB, Willett WC, Hu FB. Changes in diet and lifestyle and long-term weight gain in women and men. N Engl J Med (2011) 364:2392-404. doi:10.1056/NEJMoa1014296

9. Shoelson SE, Herrero L, Naaz A. Obesity, inflammation, and insulin resistance. Gastroenterology (2007) 132:2169-80. doi:10.1053/j.gastro.2007.03.059

10. Ley RE, Peterson DA, Gordon JI. Ecological and evolutionary forces shaping microbial diversity in the human intestine. Cell (2006) 124:837-48. doi:10.1016/j.cell.2006.02.017

11. Wood LG, Garg ML, Gibson PG. A high-fat challenge increases airway inflammation and impairs bronchodilator recovery in asthma. J Allergy Clin Immunol (2011) 127:1133-40. doi:10.1016/j.jaci.2011.01.036

12. Rocha DM, Caldas AP, Oliveira LL, Bressan J, Hermsdorff HH. Saturated fatty acids trigger TLR4-mediated inflammatory response. Atherosclerosis (2016) 244:211-5. doi:10.1016/j.atherosclerosis.2015.11.015

13. Calder PC. Fatty acids and inflammation: the cutting edge between food and pharma. Eur J Pharmacol (2011) 668(Suppl 1):S50-8. doi:10.1016/j. ejphar.2011.05.085 metabolomics or systems biology, will reveal a clearer picture of the components contributing to the pathology of these chronic inflammatory conditions. Furthermore, the impact of current therapeutic treatments and diets on disease progression and the microbiota are currently lacking, therefore, future studies addressing this question could lead to new beneficial treatment strategies.

\section{AUTHOR CONTRIBUTIONS}

DS, MA, and JM wrote the manuscript; SM wrote and edited the manuscript. All authors read and approved the final manuscript.

\section{ACKNOWLEDGMENTS}

The APC Microbiome Institute and the authors in this publication receive financial support from Science Foundation Ireland (SFI) under Grant Number SFI/12/RC/2273. The authors would like to acknowledge SERVIER INTERNATIONAL for the Servier medical art illustrations that were used in this review. The authors want to thanks Dr. Amanda Lohan for proofreading of the manuscript.

14. Hall JA, Hartman J, Skinner MM, Schwindt AR, Fischer KA, Vorachek WR, et al. Dietary enrichment with $20 \%$ fish oil decreases mucus production and the inflammatory response in mice with ovalbumin-induced allergic lung inflammation. PLoS One (2016) 11:e0163819. doi:10.1371/journal. pone.0163819

15. Klemens CM, Berman DR, Mozurkewich EL. The effect of perinatal omega-3 fatty acid supplementation on inflammatory markers and allergic diseases: a systematic review. BJOG (2011) 118:916-25. doi:10.1111/j.1471-0528.2010.02846.x

16. Engel MA, Neurath MF. New pathophysiological insights and modern treatment of IBD. J Gastroenterol (2010) 45:571-83. doi:10.1007/ s00535-010-0219-3

17. Thorburn AN, McKenzie CI, Shen S, Stanley D, Macia L, Mason LJ, et al. Evidence that asthma is a developmental origin disease influenced by maternal diet and bacterial metabolites. Nat Commun (2015) 6:7320. doi:10.1038/ ncomms 8320

18. Alavaikko S, Jaakkola MS, Tjaderhane L, Jaakkola JJ. Asthma and caries: a systematic review and meta-analysis. Am J Epidemiol (2011) 174:631-41. doi:10.1093/aje/kwr129

19. Kamada N, Kim YG, Sham HP, Vallance BA, Puente JL, Martens EC, et al. Regulated virulence controls the ability of a pathogen to compete with the gut microbiota. Science (2012) 336:1325-9. doi:10.1126/science.1222195

20. Martinez-Medina M, Denizot J, Dreux N, Robin F, Billard E, Bonnet R, et al. Western diet induces dysbiosis with increased $E$ coli in CEABAC10 mice, alters host barrier function favouring AIEC colonisation. Gut (2014) 63:116-24. doi:10.1136/gutjnl-2012-304119

21. Park S, Akinbami LJ, McGuire LC, Blanck HM. Association of sugar-sweetened beverage intake frequency and asthma among U.S. adults, 2013. Prev Med (2016) 91:58-61. doi:10.1016/j.ypmed.2016.08.004

22. Louis P, Scott KP, Duncan SH, Flint HJ. Understanding the effects of diet on bacterial metabolism in the large intestine. J Appl Microbiol (2007) 102:1197-208. doi:10.1111/j.1365-2672.2007.03322.x

23. Trompette A, Gollwitzer ES, Yadava K, Sichelstiel AK, Sprenger N, NgomBru C, et al. Gut microbiota metabolism of dietary fiber influences allergic airway disease and hematopoiesis. Nat Med (2014) 20:159-66. doi:10.1038/ nm.3444

24. Li Z, Rava M, Bedard A, Dumas O, Garcia-Aymerich J, Leynaert B, et al. Cured meat intake is associated with worsening asthma symptoms. Thorax (2017) 72:206-12. doi:10.1136/thoraxjnl-2016-208375 
25. Ufnal M, Zadlo A, Ostaszewski R. TMAO: a small molecule of great expectations. Nutrition (2015) 31:1317-23. doi:10.1016/j.nut.2015.05.006

26. Hou YC, Chu CC, Ko TL, Yeh CL, Yeh SL. Effects of alanyl-glutamine dipeptide on the expression of colon-inflammatory mediators during the recovery phase of colitis induced by dextran sulfate sodium. Eur J Nutr (2013) 52:1089-98. doi:10.1007/s00394-012-0416-3

27. Garcia-Larsen V, Del Giacco SR, Moreira A, Bonini M, Charles D, Reeves T, et al. Asthma and dietary intake: an overview of systematic reviews. Allergy (2016) 71:433-42. doi:10.1111/all.12800

28. Kang SG, Wang C, Matsumoto S, Kim CH. High and low vitamin A therapies induce distinct FoxP3+ T-cell subsets and effectively control intestinal inflammation. Gastroenterology (2009) 137:1391-402.e1391-6. doi:10.1053/j.gastro.2009.06.063

29. Abdo J, Rai V, Agrawal DK. Interplay of immunity and vitamin D: interactions and implications with current IBD therapy. Curr Med Chem (2017) 24:852-67. doi:10.2174/0929867323666161026124951

30. Yuk JM, Shin DM, Lee HM, Yang CS, Jin HS, Kim KK, et al. Vitamin D3 induces autophagy in human monocytes/macrophages via cathelicidin. Cell Host Microbe (2009) 6:231-43. doi:10.1016/j.chom.2009.08.004

31. Bailey LB, Stover PJ, McNulty H, Fenech MF, Gregory JF III, Mills JL, et al. Biomarkers of nutrition for development-folate review. J Nutr (2015) 145:1636S-80S. doi:10.3945/jn.114.206599

32. Blatter J, Brehm JM, Sordillo J, Forno E, Boutaoui N, Acosta-Perez E, et al. Folate deficiency, atopy, and severe asthma exacerbations in Puerto Rican children. Ann Am Thorac Soc (2016) 13:223-30. doi:10.1513/ AnnalsATS.201508-549OC

33. Kinoshita M, Kayama H, Kusu T, Yamaguchi T, Kunisawa J, Kiyono H, et al. Dietary folic acid promotes survival of Foxp3+ regulatory T cells in the colon. J Immunol (2012) 189:2869-78. doi:10.4049/jimmunol.1200420

34. Thuesen BH, Husemoen LL, Ovesen L, Jorgensen $T$, Fenger $M$, Gilderson $\mathrm{G}$, etal. Atopy, asthma, and lung function in relation to folate and vita$\min B(12)$ in adults. Allergy (2010) 65:1446-54. doi:10.1111/j.1398-9995.2010. 02378.x

35. Cassat JE, Skaar EP. Iron in infection and immunity. Cell Host Microbe (2013) 13:509-19. doi:10.1016/j.chom.2013.04.010

36. Perl DP, Fogarty U, Harpaz N, Sachar DB. Bacterial-metal interactions: the potential role of aluminum and other trace elements in the etiology of Crohn's disease. Inflamm Bowel Dis (2004) 10:881-3. doi:10.1097/00054725-200411000-00022

37. Lees CW, Barrett JC, Parkes M, Satsangi J. New IBD genetics: common pathways with other diseases. Gut (2011) 60(12):1739-53. doi:10.1136/ gut.2009.199679

38. Zhernakova A, van Diemen CC, Wijmenga C. Detecting shared pathogenesis from the shared genetics of immune-related diseases. Nat Rev Genet (2009) 10(1):43-55. doi:10.1038/nrg2489

39. Khor B, Gardet A, Xavier RJ. Genetics and pathogenesis of inflammatory bowel disease. Nature (2011) 474:307-17. doi:10.1038/nature10209

40. Vercelli D. Discovering susceptibility genes for asthma and allergy. Nat Rev Immunol (2008) 8(3):169-82. doi:10.1038/nri2257

41. Sullivan A, Hunt E, MacSharry J, Murphy DM. The microbiome and the pathophysiology of asthma. Respir Res (2016) 17:163. doi:10.1186/ s12931-016-0479-4

42. Huttenhower C, Kostic AD, Xavier RJ. Inflammatory bowel disease as a model for translating the microbiome. Immunity (2014) 40:843-54. doi:10.1016/j. immuni.2014.05.013

43. Melgar S, Shanahan F. Inflammatory bowel disease-from mechanisms to treatment strategies. Autoimmunity (2010) 43:463-77. doi:10.3109/ 08916931003674709

44. Lichtenstein GR, Hanauer SB, Sandborn WJ; Practice Parameters Committee of American College of Gastroenterology. Management of Crohn's disease in adults. Am J Gastroenterol (2009) 104:465-83; quiz 464, 484. doi:10.1038/ ajg. 2008.168

45. Neurath MF. Current and emerging therapeutic targets for IBD. Nat Rev Gastroenterol Hepatol (2017) 14:269-78. doi:10.1038/nrgastro.2016.208

46. Ozaki E, Campbell M, Doyle SL. Targeting the NLRP3 inflammasome in chronic inflammatory diseases: current perspectives. J Inflamm Res (2015) 8:15-27. doi:10.2147/JIR.S51250
47. Sartor RB. Microbial influences in inflammatory bowel diseases. Gastroenterology (2008) 134:577-94. doi:10.1053/j.gastro.2007.11.059

48. Perencevich M, Burakoff R. Use of antibiotics in the treatment of inflammatory bowel disease. Inflamm Bowel Dis (2006) 12:651-64. doi:10.1097/01. MIB.0000225330.38119.c7

49. Eckburg PB, Bik EM, Bernstein CN, Purdom E, Dethlefsen L, Sargent M, et al. Diversity of the human intestinal microbial flora. Science (2005) 308:1635-8. doi:10.1126/science.1110591

50. Sun L, Nava GM, Stappenbeck TS. Host genetic susceptibility, dysbiosis, and viral triggers in inflammatory bowel disease. Curr Opin Gastroenterol (2011) 27:321-7. doi:10.1097/MOG.0b013e32834661b4

51. Sokol H, Pigneur B, Watterlot L, Lakhdari O, Bermudez-Humaran LG, Gratadoux JJ, et al. Faecalibacterium prausnitzii is an anti-inflammatory commensal bacterium identified by gut microbiota analysis of Crohn disease patients. Proc Natl Acad Sci U S A (2008) 105:16731-6. doi:10.1073/ pnas. 0804812105

52. Darfeuille-Michaud A, Boudeau J, Bulois P, Neut C, Glasser AL, Barnich N, et al. High prevalence of adherent-invasive Escherichia coli associated with ileal mucosa in Crohn's disease. Gastroenterology (2004) 127:412-21. doi:10.1053/j.gastro.2004.04.061

53. Jostins L, Ripke S, Weersma RK, Duerr RH, McGovern DP, Hui KY, et al. Host-microbe interactions have shaped the genetic architecture of inflammatory bowel disease. Nature (2012) 491:119-24. doi:10.1038/ nature11582

54. Abe K, Nguyen KP, Fine SD, Mo JH, Shen C, Shenouda S, et al. Conventional dendritic cells regulate the outcome of colonic inflammation independently of T cells. Proc Natl Acad Sci U S A (2007) 104:17022-7. doi:10.1073/ pnas. 0708469104

55. Arranz A, Doxaki C, Vergadi E, Martinez de la Torre Y, Vaporidi K, Lagoudaki ED, et al. Akt1 and Akt2 protein kinases differentially contribute to macrophage polarization. Proc Natl Acad Sci U S A (2012) 109:9517-22. doi:10.1073/pnas.1119038109

56. Berndt BE, Zhang M, Chen GH, Huffnagle GB, Kao JY. The role of dendritic cells in the development of acute dextran sulfate sodium colitis. J Immunol (2007) 179:6255-62. doi:10.4049/jimmunol.179.9.6255

57. Hunter MM, Wang A, Parhar KS, Johnston MJ, Van Rooijen N, Beck PL, et al. In vitro-derived alternatively activated macrophages reduce colonic inflammation in mice. Gastroenterology (2010) 138:1395-405. doi:10.1053/j. gastro.2009.12.041

58. Qualls JE, Kaplan AM, van Rooijen N, Cohen DA. Suppression of experimental colitis by intestinal mononuclear phagocytes. J Leukoc Biol (2006) 80:802-15. doi:10.1189/jlb.1205734

59. Qualls JE, Tuna H, Kaplan AM, Cohen DA. Suppression of experimental colitis in mice by CD11c+ dendritic cells. Inflamm Bowel Dis (2009) 15:236-47. doi:10.1002/ibd.20733

60. Watanabe N, Ikuta K, Okazaki K, Nakase H, Tabata Y, Matsuura M, et al. Elimination of local macrophages in intestine prevents chronic colitis in interleukin-10-deficient mice. Dig Dis Sci (2003) 48:408-14. doi:10.1023/ A: 1021960401290

61. Coskun M. Intestinal epithelium in inflammatory bowel disease. Front Med (2014) 1:24. doi:10.3389/fmed.2014.00024

62. Neurath MF. Cytokines in inflammatory bowel disease. Nat Rev Immunol (2014) 14:329-42. doi:10.1038/nri3661

63. Fuss IJ, Heller F, Boirivant M, Leon F, Yoshida M, Fichtner-Feigl S, et al. Nonclassical CD1d-restricted NK T cells that produce IL-13 characterize an atypical Th2 response in ulcerative colitis. J Clin Invest (2004) 113:1490-7. doi:10.1172/JCI19836

64. Inoue S, Matsumoto T, Iida M, Mizuno M, Kuroki F, Hoshika K, et al. Characterization of cytokine expression in the rectal mucosa of ulcerative colitis: correlation with disease activity. Am J Gastroenterol (1999) 94:2441-6. doi:10.1111/j.1572-0241.1999.01372.x

65. Melgar S, Yeung MM, Bas A, Forsberg G, Suhr O, Oberg A, et al. Over-expression of interleukin 10 in mucosal $\mathrm{T}$ cells of patients with active ulcerative colitis. Clin Exp Immunol (2003) 134:127-37. doi:10.1046/j.1365-2249.2003.02268.x

66. Nunes C, Pereira AM, Morais-Almeida M. Asthma costs and social impact. Asthma Res Pract (2017) 3:1. doi:10.1186/s40733-016-0029-3 
67. Mitchell PD, O’Byrne PM. Biologics and the lung: TSLP and other epithelial cell-derived cytokines in asthma. Pharmacol Ther (2017) 169:104-12. doi:10.1016/j.pharmthera.2016.06.009

68. Byrne AJ, Maher TM, Lloyd CM. Pulmonary macrophages: a new therapeutic pathway in fibrosing lung disease? Trends Mol Med (2016) 22:303-16. doi:10.1016/j.molmed.2016.02.004

69. Iwasaki A, Foxman EF, Molony RD. Early local immune defences in the respiratory tract. Nat Rev Immunol (2017) 17:7-20. doi:10.1038/nri.2016.117

70. Deckers J, Branco Madeira F, Hammad H. Innate immune cells in asthma. Trends Immunol (2013) 34:540-7. doi:10.1016/j.it.2013.08.004

71. Barnes PJ. Immunology of asthma and chronic obstructive pulmonary disease. Nat Rev Immunol (2008) 8:183-92. doi:10.1038/nri2254

72. Chang HS, Lee TH, Jun JA, Baek AR, Park JS, Koo SM, et al. Neutrophilic inflammation in asthma: mechanisms and therapeutic considerations. Expert Rev Respir Med (2017) 11:29-40. doi:10.1080/17476348.2017.1268919

73. Budden KF, Gellatly SL, Wood DL, Cooper MA, Morrison M, Hugenholtz P, et al. Emerging pathogenic links between microbiota and the gut-lung axis. Nat Rev Microbiol (2017) 15:55-63. doi:10.1038/nrmicro.2016.142

74. Kumar RK, Herbert C, Foster PS. Mouse models of acute exacerbations of allergic asthma. Respirology (2016) 21:842-9. doi:10.1111/resp.12760

75. Debeuf N, Haspeslagh E, van Helden M, Hammad H, Lambrecht BN. Mouse models of asthma. Curr Protoc Mouse Biol (2016) 6:169-84. doi:10.1002/ cpmo.4

76. Ober C, Yao TC. The genetics of asthma and allergic disease: a $21 \mathrm{st}$ century perspective. Immunol Rev (2011) 242:10-30. doi:10.1111/j. 1600-065X.2011.01029.x

77. Moheimani F, Hsu AC, Reid AT, Williams T, Kicic A, Stick SM, et al. The genetic and epigenetic landscapes of the epithelium in asthma. Respir Res (2016) 17:119. doi:10.1186/s12931-016-0434-4

78. Sulovari A, Chen YH, Hudziak JJ, Li D. Atlas of human diseases influenced by genetic variants with extreme allele frequency differences. Hum Genet (2017) 136:39-54. doi:10.1007/s00439-016-1734-y

79. Forsythe P, Inman MD, Bienenstock J. Oral treatment with live Lactobacillus reuteri inhibits the allergic airway response in mice. Am J Respir Crit Care Med (2007) 175:561-9. doi:10.1164/rccm.200606-821OC

80. MacSharry J, O'Mahony C, Shalaby KH, Sheil B, Karmouty-Quintana H, Shanahan F, et al. Immunomodulatory effects of feeding with Bifidobacterium longum on allergen-induced lung inflammation in the mouse. Pulm Pharmacol Ther (2012) 25:325-34. doi:10.1016/j.pupt.2012. 05.011

81. Russell SL, Gold MJ, Reynolds LA, Willing BP, Dimitriu P, Thorson L, et al. Perinatal antibiotic-induced shifts in gut microbiota have differential effects on inflammatory lung diseases. J Allergy Clin Immunol (2015) 135:100-9. doi:10.1016/j.jaci.2014.06.027

82. Wheeler ML, Limon JJ, Bar AS, Leal CA, Gargus M, Tang J, et al. Immunological consequences of intestinal fungal dysbiosis. Cell Host Microbe (2016) 19:865-73. doi:10.1016/j.chom.2016.05.003

83. Arrieta MC, Stiemsma LT, Dimitriu PA, Thorson L, Russell S, YuristDoutsch S, et al. Early infancy microbial and metabolic alterations affect risk of childhood asthma. Sci Transl Med (2015) 7:307ra152. doi:10.1126/ scitranslmed.aab2271

84. Stiemsma LT, Arrieta MC, Dimitriu PA, Cheng J, Thorson L, Lefebvre DL, et al. Shifts in Lachnospira and Clostridium sp. in the 3-month stool microbiome are associated with preschool age asthma. Clin Sci (Lond) (2016) 130:2199-207.

85. Sonnenburg JL, Angenent LT, Gordon JI. Getting a grip on things: how do communities of bacterial symbionts become established in our intestine? Nat Immunol (2004) 5:569-73. doi:10.1038/ni1079

86. De Filippo C, Cavalieri D, Di Paola M, Ramazzotti M, Poullet JB, Massart S, et al. Impact of diet in shaping gut microbiota revealed by a comparative study in children from Europe and rural Africa. Proc Natl Acad Sci U S A (2010) 107:14691-6. doi:10.1073/pnas.1005963107

87. Geuking MB, Koller Y, Rupp S, McCoy KD. The interplay between the gut microbiota and the immune system. Gut Microbes (2014) 5:411-8. doi:10.4161/gmic.29330

88. Cani PD, Amar J, Iglesias MA, Poggi M, Knauf C, Bastelica D, et al. Metabolic endotoxemia initiates obesity and insulin resistance. Diabetes (2007) 56:1761-72. doi:10.2337/db06-1491
89. Wellen KE, Hotamisligil GS. Inflammation, stress, and diabetes. J Clin Invest (2005) 115:1111-9. doi:10.1172/JCI200525102

90. Kitamoto S, Nagao-Kitamoto H, Kuffa P, Kamada N. Regulation of virulence: the rise and fall of gastrointestinal pathogens. J Gastroenterol (2016) 51:195-205. doi:10.1007/s00535-015-1141-5

91. Jandhyala SM, Talukdar R, Subramanyam C, Vuyyuru H, Sasikala M, Nageshwar Reddy D. Role of the normal gut microbiota. World J Gastroenterol (2015) 21:8787-803. doi:10.3748/wjg.v21.i29.8787

92. Zhang C, Zhang M, Pang X, Zhao Y, Wang L, Zhao L. Structural resilience of the gut microbiota in adult mice under high-fat dietary perturbations. ISME $J$ (2012) 6:1848-57. doi:10.1038/ismej.2012.27

93. David LA, Maurice CF, Carmody RN, Gootenberg DB, Button JE, Wolfe BE, et al. Diet rapidly and reproducibly alters the human gut microbiome. Nature (2014) 505:559-63. doi:10.1038/nature12820

94. Walker AW, Ince J, Duncan SH, Webster LM, Holtrop G, Ze X, et al. Dominant and diet-responsive groups of bacteria within the human colonic microbiota. ISME J (2011) 5:220-30. doi:10.1038/ismej.2010.118

95. Lyons CL, Kennedy EB, Roche HM. Metabolic inflammation-differential modulation by dietary constituents. Nutrients (2016) 8. doi:10.3390/ nu8050247

96. Harper JW, Zisman TL. Interaction of obesity and inflammatory bowel disease. World J Gastroenterol (2016) 22:7868-81. doi:10.3748/wjg.v22. i35.7868

97. Barbier M, Vidal H, Desreumaux P, Dubuquoy L, Bourreille A, Colombel JF, et al. Overexpression of leptin mRNA in mesenteric adipose tissue in inflammatory bowel diseases. Gastroenterol Clin Biol (2003) 27:987-91.

98. Bertin B, Desreumaux P, Dubuquoy L. Obesity, visceral fat and Crohn's disease. Curr Opin Clin Nutr Metab Care (2010) 13:574-80. doi:10.1097/ MCO.0b013e32833cf0f4

99. Desreumaux P, Ernst O, Geboes K, Gambiez L, Berrebi D, Muller-Alouf $\mathrm{H}$, et al. Inflammatory alterations in mesenteric adipose tissue in Crohn's disease. Gastroenterology (1999) 117:73-81. doi:10.1016/S0016-5085(99) 70552-4

100. Rodrigues VS, Milanski M, Fagundes JJ, Torsoni AS, Ayrizono ML, Nunez CE, et al. Serum levels and mesenteric fat tissue expression of adiponectin and leptin in patients with Crohn's disease. Clin Exp Immunol (2012) 170:358-64. doi:10.1111/j.1365-2249.2012.04660.x

101. Peyrin-Biroulet L, Gonzalez F, Dubuquoy L, Rousseaux C, Dubuquoy C, Decourcelle $\mathrm{C}$, et al. Mesenteric fat as a source of $\mathrm{C}$ reactive protein and as a target for bacterial translocation in Crohn's disease. Gut (2012) 61:78-85. doi:10.1136/gutjnl-2011-300370

102. Pietsch J, Batra A, Stroh T, Fedke I, Glauben R, Okur B, et al. Toll-like receptor expression and response to specific stimulation in adipocytes and preadipocytes: on the role of fat in inflammation. Ann N Y Acad Sci (2006) 1072:407-9. doi:10.1196/annals.1326.021

103. Sheehan AL, Warren BF, Gear MW, Shepherd NA. Fat-wrapping in Crohn's disease: pathological basis and relevance to surgical practice. Br J Surg (1992) 79:955-8.

104. Borley NR, Mortensen NJ, Jewell DP, Warren BF. The relationship between inflammatory and serosal connective tissue changes in ileal Crohn's disease: evidence for a possible causative link. J Pathol (2000) 190:196-202. doi:10.1002/(SICI) 1096-9896(200002)190:2<196::AID-PATH513>3.0. $\mathrm{CO} ; 2-5$

105. Olivier I, Theodorou V, Valet P, Castan-Laurell I, Guillou H, Bertrand-Michel J, et al. Is Crohn's creeping fat an adipose tissue? Inflamm Bowel Dis (2011) 17(3):747-57. doi:10.1002/ibd.21413

106. Dubuquoy L, Rousseaux C, Thuru X, Peyrin-Biroulet L, Romano O, Chavatte P, et al. PPARgamma as a new therapeutic target in inflammatory bowel diseases. Gut (2006) 55:1341-9. doi:10.1136/gut.2006.093484

107. Mansen A, Guardiola-Diaz H, Rafter J, Branting C, Gustafsson JA. Expression of the peroxisome proliferator-activated receptor (PPAR) in the mouse colonic mucosa. Biochem Biophys Res Commun (1996) 222:844-51. doi:10.1006/bbrc.1996.0832

108. Kim HY, Lee HJ, Chang YJ, Pichavant M, Shore SA, Fitzgerald KA, et al. Interleukin-17-producing innate lymphoid cells and the NLRP3 inflammasome facilitate obesity-associated airway hyperreactivity. Nat Med (2014) 20:54-61. doi:10.1038/nm.3423 
109. Gevers D, Kugathasan S, Denson LA, Vazquez-Baeza Y, Van Treuren W, Ren B, et al. The treatment-naive microbiome in new-onset Crohn's disease. Cell Host Microbe (2014) 15:382-92. doi:10.1016/j.chom.2014.02.005

110. Halmos EP, Gibson PR. Dietary management of IBD - insights and advice. Nat Rev Gastroenterol Hepatol (2015) 12:133-46. doi:10.1038/nrgastro. 2015.11

111. Shivashankar R, Lewis JD. The role of diet in inflammatory bowel disease. Curr Gastroenterol Rep (2017) 19:22. doi:10.1007/s11894-017-0563-z

112. Willemsen LE. Dietary n-3 long chain polyunsaturated fatty acids in allergy prevention and asthma treatment. Eur J Pharmacol (2016) 785:174-86. doi:10.1016/j.ejphar.2016.03.062

113. Chan SS, Luben R, Olsen A, Tjonneland A, Kaaks R, Teucher B, et al. Body mass index and the risk for Crohn's disease and ulcerative colitis: data from a European Prospective Cohort Study (The IBD in EPIC study). Am J Gastroenterol (2013) 108:575-82. doi:10.1038/ajg.2012.453

114. de Silva PS, Luben R, Shrestha SS, Khaw KT, Hart AR. Dietary arachidonic and oleic acid intake in ulcerative colitis etiology: a prospective cohort study using 7-day food diaries. Eur J Gastroenterol Hepatol (2014) 26:11-8. doi:10.1097/MEG.0b013e328365c372

115. Wiese DM, Horst SN, Brown CT, Allaman MM, Hodges ME, Slaughter JC, et al. Serum fatty acids are correlated with inflammatory cytokines in ulcerative colitis. PLoS One (2016) 11:e0156387. doi:10.1371/ journal.pone.0156387

116. Ferreira P, Cravo M, Guerreiro CS, Tavares L, Santos PM, Brito M. Fat intake interacts with polymorphisms of Caspase9, FasLigand and PPARgamma apoptotic genes in modulating Crohn's disease activity. Clin Nutr (2010) 29:819-23. doi:10.1016/j.clnu.2010.06.008

117. Nagel G, Linseisen J. Dietary intake of fatty acids, antioxidants and selected food groups and asthma in adults. Eur J Clin Nutr (2005) 59:8-15. doi:10.1038/sj.ejcn.1602025

118. Wijga AH, Smit HA, Kerkhof M, de Jongste JC, Gerritsen J, Neijens HJ, et al. Association of consumption of products containing milk fat with reduced asthma risk in pre-school children: the PIAMA birth cohort study. Thorax (2003) 58:567-72. doi:10.1136/thorax.58.7.567

119. Yang ZH, Miyahara H, Takeo J, Katayama M. Diet high in fat and sucrose induces rapid onset of obesity-related metabolic syndrome partly through rapid response of genes involved in lipogenesis, insulin signalling and inflammation in mice. Diabetol Metab Syndr (2012) 4:32. doi:10.1186/1758-5996-4-32

120. Miller B, Fervers F, Rohbeck R, Strohmeyer G. [Sugar consumption in patients with Crohn's disease]. Verh Dtsch Ges Inn Med (1976) 82(Pt 1):922-4.

121. Racine A, Carbonnel F, Chan SS, Hart AR, Bueno-de-Mesquita HB, Oldenburg B, et al. Dietary patterns and risk of inflammatory bowel disease in Europe: results from the EPIC study. Inflamm Bowel Dis (2016) 22:345-54. doi:10.1097/MIB.0000000000000638

122. Berentzen NE, van Stokkom VL, Gehring U, Koppelman GH, Schaap LA, Smit HA, et al. Associations of sugar-containing beverages with asthma prevalence in 11-year-old children: the PIAMA birth cohort. Eur J Clin Nutr (2015) 69:303-8. doi:10.1038/ejcn.2014.153

123. Agus A, Denizot J, Thevenot J, Martinez-Medina M, Massier S, Sauvanet P, et al. Western diet induces a shift in microbiota composition enhancing susceptibility to adherent-invasive $E$. coli infection and intestinal inflammation. Sci Rep (2016) 6:19032. doi:10.1038/srep19032

124. Shoda R, Matsueda K, Yamato S, Umeda N. Epidemiologic analysis of Crohn disease in Japan: increased dietary intake of n- 6 polyunsaturated fatty acids and animal protein relates to the increased incidence of Crohn disease in Japan. Am J Clin Nutr (1996) 63:741-5.

125. Maconi G, Ardizzone S, Cucino C, Bezzio C, Russo AG, Bianchi Porro G. Pre-illness changes in dietary habits and diet as a risk factor for inflammatory bowel disease: a case-control study. World J Gastroenterol (2010) 16:4297-304. doi:10.3748/wjg.v16.i34.4297

126. Devkota S, Wang Y, Musch MW, Leone V, Fehlner-Peach H, Nadimpalli A, et al. Dietary-fat-induced taurocholic acid promotes pathobiont expansion and colitis in Il10-/- mice. Nature (2012) 487:104-8. doi:10.1038/ nature 11225

127. Wright R, Truelove SC. A controlled therapeutic trial of various diets in ulcerative colitis. Br Med J (1965) 2:138-41. doi:10.1136/bmj.2.4724.138

128. Campbell BE, Lodge CJ, Lowe AJ, Burgess JA, Matheson MC, DharmageSC.Exposureto'farming' andobjectivemarkersofatopy:asystematic review and meta-analysis. Clin Exp Allergy (2015) 45:744-57. doi:10.1111/ cea. 12429

129. House JS, Wyss AB, Hoppin JA, Richards M, Long S, Umbach DM, et al. Early-life farm exposures and adult asthma and atopy in the Agricultural Lung Health Study. J Allergy Clin Immunol (2017) 140(1):249-56.e214. doi:10.1016/j.jaci.2016.09.036

130. Sozanska B, Pearce N, Dudek K, Cullinan P. Consumption of unpasteurized milk and its effects on atopy and asthma in children and adult inhabitants in rural Poland. Allergy (2013) 68:644-50. doi:10.1111/all.12147

131. Roberts CL, Rushworth SL, Richman E, Rhodes JM. Hypothesis: increased consumption of emulsifiers as an explanation for the rising incidence of Crohn's disease. J Crohns Colitis (2013) 7:338-41. doi:10.1016/j.crohns. 2013.01.004

132. Chassaing B, Koren O, Goodrich JK, Poole AC, Srinivasan S, Ley RE, et al. Dietary emulsifiers impact the mouse gut microbiota promoting colitis and metabolic syndrome. Nature (2015) 519:92-6. doi:10.1038/nature14232

133. Roberts CL, Keita AV, Duncan SH, O’Kennedy N, Soderholm JD, Rhodes JM, et al. Translocation of Crohn's disease Escherichia coli across M-cells: contrasting effects of soluble plant fibres and emulsifiers. Gut (2010) 59:1331-9. doi:10.1136/gut.2009.195370

134. Chassaing B, Van de Wiele T, De Bodt J, Marzorati M, Gewirtz AT. Dietary emulsifiers directly alter human microbiota composition and gene expression ex vivo potentiating intestinal inflammation. Gut (2017). doi:10.1136/ gutjnl-2016-313099

135. Hou JK, Lee D, Lewis J. Diet and inflammatory bowel disease: review of patient-targeted recommendations. Clin Gastroenterol Hepatol (2014) 12:1592-600. doi:10.1016/j.cgh.2013.09.063

136. Chan SS, Luben R, van Schaik F, Oldenburg B, Bueno-de-Mesquita HB, Hallmans G, et al. Carbohydrate intake in the etiology of Crohn's disease and ulcerative colitis. Inflamm Bowel Dis (2014) 20:2013-21. doi:10.1097/ MIB.0000000000000168

137. Lucendo AJ, De Rezende LC. Importance of nutrition in inflammatory bowel disease. World J Gastroenterol (2009) 15:2081-8. doi:10.3748/wjg. 15.2081

138. Ananthakrishnan AN, Khalili H, Konijeti GG, Higuchi LM, de Silva P, Korzenik JR, et al. A prospective study of long-term intake of dietary fiber and risk of Crohn's disease and ulcerative colitis. Gastroenterology (2013) 145:970-7. doi:10.1053/j.gastro.2013.07.050

139. Monteleone I, Pallone F, Monteleone G. Aryl hydrocarbon receptor and colitis. Semin Immunopathol (2013) 35:671-5. doi:10.1007/s00281-0130396-2

140. Li Y, Innocentin S, Withers DR, Roberts NA, Gallagher AR, Grigorieva EF, et al. Exogenous stimuli maintain intraepithelial lymphocytes via aryl hydrocarbon receptor activation. Cell (2011) 147:629-40. doi:10.1016/j.cell.2011.09.025

141. Monteleone I, Rizzo A, Sarra M, Sica G, Sileri P, Biancone L, et al. Aryl hydrocarbon receptor-induced signals up-regulate IL-22 production and inhibit inflammation in the gastrointestinal tract. Gastroenterology (2011) 141:237-248, 248.e231. doi:10.1053/j.gastro.2011.04.007

142. Qiu Y, Peng K, Liu M, Xiao W, Yang H. CD8alphaalpha TCRalphabeta intraepithelial lymphocytes in the mouse gut. Dig Dis Sci (2016) 61:1451-60. doi:10.1007/s10620-015-4016-y

143. Leibelt S, Friede ME, Rohe C, Gutle D, Rutkowski E, Weigert A, et al. Dedicated immunosensing of the mouse intestinal epithelium facilitated by a pair of genetically coupled lectin-like receptors. Mucosal Immunol (2015) 8:232-42. doi:10.1038/mi.2014.60

144. Schmitz F, Kooy-Winkelaar Y, Wiekmeijer AS, Brugman MH, Mearin $\mathrm{ML}$, Mulder C, et al. The composition and differentiation potential of the duodenal intraepithelial innate lymphocyte compartment is altered in coeliac disease. Gut (2016) 65:1269-78. doi:10.1136/gutjnl-2014308153

145. Grimstad T, Berge RK, Bohov P, Skorve J, Goransson L, Omdal R, et al. Salmon diet in patients with active ulcerative colitis reduced the simple clinical colitis activity index and increased the anti-inflammatory fatty acid index - a pilot study. Scand J Clin Lab Invest (2011) 71:68-73. doi:10.3109/0 0365513.2010.542484

146. Yang H, Xun P, He K. Fish and fish oil intake in relation to risk of asthma: a systematic review and meta-analysis. PLoS One (2013) 8:e80048. doi:10.1371/journal.pone.0080048 
147. Vannice G, Rasmussen H. Position of the academy of nutrition and dietetics: dietary fatty acids for healthy adults. J Acad Nutr Diet 114(1):136-53. doi:10.1016/j.jand.2013.11.001

148. Huang S, Rutkowsky JM, Snodgrass RG, Ono-Moore KD, Schneider DA, Newman JW, et al. Saturated fatty acids activate TLR-mediated proinflammatory signaling pathways. J Lipid Res (2012) 53:2002-13. doi:10.1194/jlr. D029546

149. Yang X, Haghiac M, Glazebrook P, Minium J, Catalano PM, Hauguelde Mouzon S. Saturated fatty acids enhance TLR4 immune pathways in human trophoblasts. Hum Reprod (2015) 30:2152-9. doi:10.1093/humrep/ $\operatorname{dev} 173$

150. Lee JY, Ye J, Gao Z, Youn HS, Lee WH, Zhao L, et al. Reciprocal modulation of toll-like receptor-4 signaling pathways involving MyD88 and phosphatidylinositol 3-kinase/AKT by saturated and polyunsaturated fatty acids. J Biol Chem (2003) 278:37041-51. doi:10.1074/jbc.M305213200

151. Moreira AP, Texeira TF, Ferreira AB, Peluzio Mdo C, Alfenas Rde C. Influence of a high-fat diet on gut microbiota, intestinal permeability and metabolic endotoxaemia. Br J Nutr (2012) 108:801-9. doi:10.1017/S0007114512001213

152. Fernandez ML, West KL. Mechanisms by which dietary fatty acids modulate plasma lipids. J Nutr (2005) 135:2075-8.

153. Stewart CR, Stuart LM, Wilkinson K, van Gils JM, Deng J, Halle A, et al. CD36 ligands promote sterile inflammation through assembly of a toll-like receptor 4 and 6 heterodimer. Nat Immunol (2010) 11:155-61. doi:10.1038/ ni. 1836

154. Gruber L, Kisling S, Lichti P, Martin FP, May S, Klingenspor M, et al. High fat diet accelerates pathogenesis of murine Crohn's disease-like ileitis independently of obesity. PLoS One (2013) 8:e71661. doi:10.1371/journal. pone. 0071661

155. Paik J, Fierce Y, Treuting PM, Brabb T, Maggio-Price L. High-fat diet-induced obesity exacerbates inflammatory bowel disease in genetically susceptible Mdr1a-/- male mice. J Nutr (2013) 143:1240-7. doi:10.3945/jn.113.174615

156. Reddy KV, Naidu KA. Oleic acid, hydroxytyrosol and n-3 fatty acids collectively modulate colitis through reduction of oxidative stress and IL-8 synthesis; in vitro and in vivo studies. Int Immunopharmacol (2016) 35:29-42. doi:10.1016/j.intimp.2016.03.019

157. Jenkins DJ, Chiavaroli L, Wong JM, Kendall C, Lewis GF, Vidgen E, et al. Adding monounsaturated fatty acids to a dietary portfolio of cholesterol-lowering foods in hypercholesterolemia. CMAJ (2010) 182:1961-7. doi:10.1503/ cmaj.092128

158. Chan KL, Pillon NJ, Sivaloganathan DM, Costford SR, Liu Z, Theret M, et al. Palmitoleate reverses high fat-induced proinflammatory macrophage polarization via AMP-activated protein kinase (AMPK). J Biol Chem (2015) 290:16979-88. doi:10.1074/jbc.M115.646992

159. Sawai T, Drongowski RA, Lampman RW, Coran AG, Harmon CM. The effect of phospholipids and fatty acids on tight-junction permeability and bacterial translocation. Pediatr Surg Int (2001) 17:269-74. doi:10.1007/s003830100592

160. Emmanouil E, Manios Y, Grammatikaki E, Kondaki K, Oikonomou E, Papadopoulos N, et al. Association of nutrient intake and wheeze or asthma in a Greek pre-school population. Pediatr Allergy Immunol (2010) 21:90-5. doi:10.1111/j.1399-3038.2009.00876.x

161. DeCoffe D, Quin C, Gill SK, Tasnim N, Brown K, Godovannyi A, et al. Dietary lipid type, rather than total number of calories, alters outcomes of enteric infection in mice. J Infect Dis (2016) 213:1846-56. doi:10.1093/infdis/ jiw084

162. Estaki M, DeCoffe D, Gibson DL. Interplay between intestinal alkaline phosphatase, diet, gut microbes and immunity. World J Gastroenterol (2014) 20:15650-6. doi:10.3748/wjg.v20.i42.15650

163. Sanchez-Fidalgo S, Cardeno A, Sanchez-Hidalgo M, Aparicio-Soto M, Villegas I, Rosillo MA, et al. Dietary unsaponifiable fraction from extra virgin olive oil supplementation attenuates acute ulcerative colitis in mice. Eur J Pharm Sci (2013) 48:572-81. doi:10.1016/j.ejps.2012.12.004

164. Cardeno A, Magnusson MK, Strid H, Alarcon de La Lastra C, SanchezHidalgo M, Ohman L. The unsaponifiable fraction of extra virgin olive oil promotes apoptosis and attenuates activation and homing properties of T cells from patients with inflammatory bowel disease. Food Chem (2014) 161:353-60. doi:10.1016/j.foodchem.2014.04.016

165. Chapkin RS, Kim W, Lupton JR, McMurray DN. Dietary docosahexaenoic and eicosapentaenoic acid: emerging mediators of inflammation. Prostaglandins
Leukot Essent Fatty Acids (2009) 81:187-91. doi:10.1016/j.plefa.2009. 05.010

166. Schmitz G, Ecker J. The opposing effects of n-3 and n-6 fatty acids. Prog Lipid Res (2008) 47:147-55. doi:10.1016/j.plipres.2007.12.004

167. Stenson WF. The universe of arachidonic acid metabolites in inflammatory bowel disease: can we tell the good from the bad? Curr Opin Gastroenterol (2014) 30:347-51. doi:10.1097/MOG.0000000000000075

168. Lee JY, Plakidas A, Lee WH, Heikkinen A, Chanmugam P, Bray G, et al. Differential modulation of toll-like receptors by fatty acids: preferential inhibition by n-3 polyunsaturated fatty acids. J Lipid Res (2003) 44:479-86. doi:10.1194/jlr.M200361-JLR200

169. Oh DY, Talukdar S, Bae EJ, Imamura T, Morinaga H, Fan W, et al. GPR120 is an omega-3 fatty acid receptor mediating potent anti-inflammatory and insulin-sensitizing effects. Cell (2010) 142:687-98. doi:10.1016/j.cell. 2010.07.041

170. Barbalho SM, Goulart Rde A, Quesada K, Bechara MD, de Carvalho Ade C. Inflammatory bowel disease: can omega- 3 fatty acids really help? Ann Gastroenterol (2016) 29:37-43.

171. Tabbaa M, Golubic M, Roizen MF, Bernstein AM. Docosahexaenoic acid, inflammation, and bacterial dysbiosis in relation to periodontal disease, inflammatory bowel disease, and the metabolic syndrome. Nutrients (2013) 5:3299-310. doi:10.3390/nu5083299

172. Liu Y, Chen F, Odle J, Lin X, Jacobi SK, Zhu H, et al. Fish oil enhances intestinal integrity and inhibits TLR4 and NOD2 signaling pathways in weaned pigs after LPS challenge. J Nutr (2012) 142:2017-24. doi:10.3945/jn. 112.164947

173. Emelyanov A, Fedoseev G, Krasnoschekova O, Abulimity A, Trendeleva T, Barnes PJ. Treatment of asthma with lipid extract of New Zealand greenlipped mussel: a randomised clinical trial. Eur Respir J (2002) 20:596-600. doi:10.1183/09031936.02.02632001

174. Mickleborough TD, Lindley MR, Ionescu AA, Fly AD. Protective effect of fish oil supplementation on exercise-induced bronchoconstriction in asthma. Chest (2006) 129:39-49. doi:10.1378/chest.129.1.39

175. Hardy MS, Kekic A, Graybill NL, Lancaster ZR. A systematic review of the association between fish oil supplementation and the development of asthma exacerbations. SAGE Open Med (2016) 4:2050312116666216. doi:10.1177/2050312116666216

176. Blasbalg TL, Hibbeln JR, Ramsden CE, Majchrzak SF, Rawlings RR. Changes in consumption of omega- 3 and omega- 6 fatty acids in the United States during the 20th century. Am J Clin Nutr (2011) 93:950-62. doi:10.3945/ ajcn. 110.006643

177. Simopoulos AP. The importance of the omega-6/omega-3 fatty acid ratio in cardiovascular disease and other chronic diseases. Exp Biol Med (Maywood) (2008) 233:674-88. doi:10.3181/0711-MR-311

178. Pearl DS, Masoodi M, Eiden M, Brummer J, Gullick D, McKeever TM, et al. Altered colonic mucosal availability of $n-3$ and $n-6$ polyunsaturated fatty acids in ulcerative colitis and the relationship to disease activity. JCrohns Colitis (2014) 8:70-9. doi:10.1016/j.crohns.2013.03.013

179. Kompauer I, Demmelmair H, Koletzko B, Bolte G, Linseisen J, Heinrich J. n6/n3 hypothesis and allergies: biologically plausible, but not confirmed. Eur J Med Res (2004) 9:378-82.

180. Sonnenburg ED, Sonnenburg JL. Starving our microbial self: the deleterious consequences of a diet deficient in microbiota-accessible carbohydrates. Cell Metab (2014) 20:779-86. doi:10.1016/j.cmet.2014.07.003

181. Cummings JH, Macfarlane GT. Role of intestinal bacteria in nutrient metabolism. JPEN J Parenter Enteral Nutr (1997) 21:357-65. doi:10.1177/0148607 197021006357

182. Maslowski KM, Mackay CR. Diet, gut microbiota and immune responses. Nat Immunol (2011) 12:5-9. doi:10.1038/ni0111-5

183. Hamer HM, Jonkers D, Venema K, Vanhoutvin S, Troost FJ, Brummer RJ. Review article: the role of butyrate on colonic function. Aliment Pharmacol Ther (2008) 27:104-19. doi:10.1111/j.1365-2036.2007.03562.x

184. Arpaia N, Campbell C, Fan X, Dikiy S, van der Veeken J, deRoos P, et al. Metabolites produced by commensal bacteria promote peripheral regulatory T-cell generation. Nature (2013) 504:451-5. doi:10.1038/nature12726

185. Josefowicz SZ, Niec RE, Kim HY, Treuting P, Chinen T, Zheng Y, et al. Extrathymically generated regulatory T cells control mucosal TH2 inflammation. Nature (2012) 482:395-9. doi:10.1038/nature10772 
186. Millard AL, Mertes PM, Ittelet D, Villard F, Jeannesson P, Bernard J. Butyrate affects differentiation, maturation and function of human monocyte-derived dendritic cells and macrophages. Clin Exp Immunol (2002) 130:245-55. doi:10.1046/j.0009-9104.2002.01977.x

187. Wang B, Morinobu A, Horiuchi M, Liu J, Kumagai S. Butyrate inhibits functional differentiation of human monocyte-derived dendritic cells. Cell Immunol (2008) 253:54-8. doi:10.1016/j.cellimm.2008.04.016

188. Koh A, De Vadder F, Kovatcheva-Datchary P, Backhed F. From dietary fiber to host physiology: short-chain fatty acids as key bacterial metabolites. Cell (2016) 165:1332-45. doi:10.1016/j.cell.2016.05.041

189. Annese V, Rogai F, Settesoldi A, Bagnoli S. PPARgamma in inflammatory bowel disease. PPAR Res (2012) 2012:620839. doi:10.1155/2012/620839

190. Frank DN, St Amand AL, Feldman RA, Boedeker EC, Harpaz N, Pace NR. Molecular-phylogenetic characterization of microbial community imbalances in human inflammatory bowel diseases. Proc Natl Acad Sci U S A (2007) 104:13780-5. doi:10.1073/pnas.0706625104

191. Machiels K, Joossens M, Sabino J, De Preter V, Arijs I, Eeckhaut V, et al. A decrease of the butyrate-producing species Roseburia hominis and Faecalibacterium prausnitzii defines dysbiosis in patients with ulcerative colitis. Gut (2014) 63:1275-83. doi:10.1136/gutjnl-2013-304833

192. Zhang T, Ding C, Zhao M, Dai X, Yang J, Li Y, et al. Sodium butyrate reduces colitogenic immunoglobulin A-coated bacteria and modifies the composition of microbiota in IL-10 deficient mice. Nutrients (2016) 8. doi:10.3390/ nu8120728

193. Gollwitzer ES, Saglani S, Trompette A, Yadava K, Sherburn R, McCoy KD, et al. Lung microbiota promotes tolerance to allergens in neonates via PD-L1. Nat Med (2014) 20:642-7. doi:10.1038/nm.3568

194. Halnes I, Baines KJ, Berthon BS, MacDonald-Wicks LK, Gibson PG, Wood LG. Soluble fibre meal challenge reduces airway inflammation and expression of GPR43 and GPR41 in asthma. Nutrients (2017) 9(1). doi:10.3390/nu9010057

195. Zhang Z, Shi L, Pang W, Liu W, Li J, Wang H, et al. Dietary fiber intake regulates intestinal microflora and inhibits ovalbumin-induced allergic airway inflammation in a mouse model. PLoS One (2016) 11:e0147778. doi:10.1371/ journal.pone. 0147778

196. Jantchou P, Morois S, Clavel-Chapelon F, Boutron-Ruault MC, Carbonnel F. Animal protein intake and risk of inflammatory bowel disease: the E3N prospective study. Am J Gastroenterol (2010) 105:2195-201. doi:10.1038/ajg.2010.192

197. Bremer J.Carnitine - metabolism and functions. Physiol Rev (1983) 63:1420-80.

198. Koeth RA, Wang Z, Levison BS, Buffa JA, Org E, Sheehy BT, et al. Intestinal microbiota metabolism of $\mathrm{L}$-carnitine, a nutrient in red meat, promotes atherosclerosis. Nat Med (2013) 19:576-85. doi:10.1038/nm.3145

199. Wilson A, Teft WA, Morse BL, Choi YH, Woolsey S, DeGorter MK, et al. Trimethylamine-N-oxide: a novel biomarker for the identification of inflammatory bowel disease. Dig Dis Sci (2015) 60:3620-30. doi:10.1007/ s10620-015-3797-3

200. Hodge L, Salome CM, Peat JK, Haby MM, Xuan W, Woolcock AJ. Consumption of oily fish and childhood asthma risk. Med J Aust (1996) 164: $137-40$.

201. Gupta NK, Thaker AI, Kanuri N, Riehl TE, Rowley CW, Stenson WF, et al. Serum analysis of tryptophan catabolism pathway: correlation with Crohn's disease activity. Inflamm Bowel Dis (2012) 18:1214-20. doi:10.1002/ ibd. 21849

202. Kim CJ, Kovacs-Nolan JA, Yang C, Archbold T, Fan MZ, Mine Y. LTryptophan exhibits therapeutic function in a porcine model of dextran sodium sulfate (DSS)-induced colitis. J Nutr Biochem (2010) 21:468-75. doi:10.1016/j.jnutbio.2009.01.019

203. Thurnham DI. Micronutrients and immune function: some recent developments. J Clin Pathol (1997) 50:887-91. doi:10.1136/jcp.50.11.887

204. Weisshof R, Chermesh I. Micronutrient deficiencies in inflammatory bowel disease. Curr Opin Clin Nutr Metab Care (2015) 18:576-81. doi:10.1097/ MCO.0000000000000226

205. Allen S, Britton JR, Leonardi-Bee JA. Association between antioxidant vitamins and asthma outcome measures: systematic review and meta-analysis. Thorax (2009) 64:610-9. doi:10.1136/thx.2008.101469

206. Burkholder PR, McVeigh I. Synthesis of vitamins by intestinal bacteria. Proc Natl Acad Sci U S A (1942) 28:285-9. doi:10.1073/pnas.28.7.285
207. Rossi M, Amaretti A, Raimondi S. Folate production by probiotic bacteria. Nutrients (2011) 3:118-34. doi:10.3390/nu3010118

208. Mora JR, Iwata M, Eksteen B, Song SY, Junt T, Senman B, et al. Generation of gut-homing IgA-secreting B cells by intestinal dendritic cells. Science (2006) 314:1157-60. doi:10.1126/science.1132742

209. Goverse G, Labao-Almeida C, Ferreira M, Molenaar R, Wahlen S, Konijn T, et al. Vitamin A controls the presence of RORgamma+ innate lymphoid cells and lymphoid tissue in the small intestine. J Immunol (2016) 196:5148-55. doi:10.4049/jimmunol.1501106

210. Seo GY, Jang YS, Kim HA, Lee MR, Park MH, Park SR, et al. Retinoic acid, acting as a highly specific IgA isotype switch factor, cooperates with TGFbetal to enhance the overall IgA response. J Leukoc Biol (2013) 94:325-35. doi:10.1189/jlb.0313128

211. Iwata M, Hirakiyama A, Eshima Y, Kagechika H, Kato C, Song SY. Retinoic acid imprints gut-homing specificity on T cells. Immunity (2004) 21:527-38. doi:10.1016/j.immuni.2004.08.011

212. Ruiter B, Patil SU, Shreffler WG. Vitamins A and D have antagonistic effects on expression of effector cytokines and gut-homing integrin in human innate lymphoid cells. Clin Exp Allergy (2015) 45:1214-25. doi:10.1111/cea.12568

213. Sirisinha S. The pleiotropic role of vitamin A in regulating mucosal immunity. Asian Pac J Allergy Immunol (2015) 33:71-89.

214. Tejon G, Manriquez V, De Calisto J, Flores-Santibanez F, Hidalgo Y, Crisostomo N, et al. Vitamin A impairs the reprogramming of Tregs into IL-17-producing cells during intestinal inflammation. Biomed Res Int (2015) 2015:137893. doi:10.1155/2015/137893

215. Fransen K, Franzen P, Magnuson A, Elmabsout AA, Nyhlin N, Wickbom A, et al. Polymorphism in the retinoic acid metabolizing enzyme CYP26B1 and the development of Crohn's disease. PLoS One (2013) 8:e72739. doi:10.1371/journal.pone.0072739

216. Bai A, Lu N, Guo Y, Liu Z, Chen J, Peng Z. All-trans retinoic acid down-regulates inflammatory responses by shifting the Treg/Th17 profile in human ulcerative and murine colitis. J Leukoc Biol (2009) 86:959-69. doi:10.1189/ jlb.0109006

217. Conway TF, Hammer L, Furtado S, Mathiowitz E, Nicoletti F, Mangano K, et al. Oral delivery of particulate transforming growth factor beta 1 and all-trans retinoic acid reduces gut inflammation in murine models of inflammatory bowel disease. J Crohns Colitis (2015) 9:647-58. doi:10.1093/ ecco-jcc/jjv089

218. Penny HL, Prestwood TR, Bhattacharya N, Sun F, Kenkel JA, Davidson MG, et al. Restoring retinoic acid attenuates intestinal inflammation and tumorigenesis in APCMin/+ mice. Cancer Immunol Res (2016) 4:917-26. doi:10.1158/2326-6066.CIR-15-0038

219. McDaniel KL, Restori KH, Dodds JW, Kennett MJ, Ross AC, Cantorna MT. Vitamin A-deficient hosts become nonsymptomatic reservoirs of Escherichia coli-like enteric infections. Infect Immun (2015) 83:2984-91. doi:10.1128/ IAI.00201-15

220. Ruane D, Chorny A, Lee H, Faith J, Pandey G, Shan M, et al. Microbiota regulate the ability of lung dendritic cells to induce IgA class-switch recombination and generate protective gastrointestinal immune responses. J Exp Med (2016) 213:53-73. doi:10.1084/jem.20150567

221. Barbachano A, Fernandez-Barral A, Ferrer-Mayorga G, Costales-Carrera A, Larriba MJ, Munoz A. The endocrine vitamin D system in the gut. Mol Cell Endocrinol (2016). doi:10.1016/j.mce.2016.11.028

222. Christakos S, Dhawan P, Verstuyf A, Verlinden L, Carmeliet G. Vitamin D: metabolism, molecular mechanism of action, and pleiotropic effects. Physiol Rev (2016) 96:365-408. doi:10.1152/physrev.00014.2015

223. Yamamoto T, Nakahigashi M, Saniabadi AR. Review article: diet and inflammatory bowel disease-epidemiology and treatment. Aliment Pharmacol Ther (2009) 30(2):99-112.

224. Simmons JD, Mullighan C, Welsh KI, Jewell DP. Vitamin D receptor gene polymorphism: association with Crohn's disease susceptibility. Gut (2000) 47:211-4. doi:10.1136/gut.47.2.211

225. Nurmatov U, Devereux G, Sheikh A. Nutrients and foods for the primary prevention of asthma and allergy: systematic review and meta-analysis. J Allergy Clin Immunol (2011) 127:724-33.e721-30. doi:10.1016/j.jaci.2010.11.001

226. Kim SH, Pei QM, Jiang P, Yang M, Qian XJ, Liu JB. Effect of active vitamin D3 on VEGF-induced ADAM33 expression and proliferation in human airway smooth muscle cells: implications for asthma treatment. Respir Res (2017) 18:7. doi:10.1186/s12931-016-0490-9 
227. Margolis RN, Christakos S. The nuclear receptor superfamily of steroid hormones and vitamin D gene regulation. An update. Ann N Y Acad Sci (2010) 1192:208-14. doi:10.1111/j.1749-6632.2009.05227.x

228. Liu W, Chen Y, Golan MA, Annunziata ML, Du J, Dougherty U, et al. Intestinal epithelial vitamin $\mathrm{D}$ receptor signaling inhibits experimental colitis. J Clin Invest (2013) 123:3983-96. doi:10.1172/JCI65842

229. Ordonez-Moran P, Larriba MJ, Palmer HG, Valero RA, Barbachano A, Dunach M, et al. RhoA-ROCK and p38MAPK-MSK1 mediate vitamin D effects on gene expression, phenotype, and Wnt pathway in colon cancer cells. J Cell Biol (2008) 183:697-710. doi:10.1083/jcb.200803020

230. Golan MA, Liu W, Shi Y, Chen L, Wang J, Liu T, et al. Transgenic expression of vitamin $\mathrm{D}$ receptor in gut epithelial cells ameliorates spontaneous colitis caused by interleukin-10 deficiency. Dig Dis Sci (2015) 60:1941-7. doi:10.1007/s10620-015-3634-8

231. Ooi JH, Li Y, Rogers CJ, Cantorna MT. Vitamin D regulates the gut microbiome and protects mice from dextran sodium sulfate-induced colitis. J Nutr (2013) 143:1679-86. doi:10.3945/jn.113.180794

232. Ryz NR, Patterson SJ, Zhang Y, Ma C, Huang T, Bhinder G, et al. Active vitamin D (1,25-dihydroxyvitamin D3) increases host susceptibility to Citrobacter rodentium by suppressing mucosal Th17 responses. Am J Physiol Gastrointest Liver Physiol (2012) 303:G1299-311. doi:10.1152/ ajpgi.00320.2012

233. Assa A, Vong L, Pinnell LJ, Rautava J, Avitzur N, Johnson-Henry KC, et al. Vitamin D deficiency predisposes to adherent-invasive Escherichia coli-induced barrier dysfunction and experimental colonic injury. Inflamm Bowel Dis (2015) 21:297-306. doi:10.1097/MIB.0000000000000282

234. Su D, Nie Y, Zhu A, Chen Z, Wu P, Zhang L, et al. Vitamin D signaling through induction of Paneth cell defensins maintains gut microbiota and improves metabolic disorders and hepatic steatosis in animal models. Front Physiol (2016) 7:498. doi:10.3389/fphys.2016.00498

235. Hoffman R. Thiamine deficiency in the Western diet and dementia risk. Br J Nutr (2016) 116:188-9. doi:10.1017/S000711451600177X

236. Kiela PR, Ghishan FK. Physiology of intestinal absorption and secretion. Best Pract Res Clin Gastroenterol (2016) 30:145-59. doi:10.1016/j.bpg. 2016.02.007

237. Knecht C, Fretter C, Rosenstiel P, Krawczak M, Hutt MT. Distinct metabolic network states manifest in the gene expression profiles of pediatric inflammatory bowel disease patients and controls. Sci Rep (2016) 6:32584. doi:10.1038/srep32584

238. Quince C, Ijaz UZ, Loman N, Eren AM, Saulnier D, Russell J, et al. Extensive modulation of the fecal metagenome in Children with Crohn's disease during exclusive enteral nutrition. Am J Gastroenterol (2015) 110:1718-29; quiz 1730. doi:10.1038/ajg.2015.357

239. Mooney S, Leuendorf JE, Hendrickson C, Hellmann H. Vitamin B6: a long known compound of surprising complexity. Molecules (2009) 14:329-51. doi:10.3390/molecules14010329

240. Selhub J, Byun A, Liu Z, Mason JB, Bronson RT, Crott JW. Dietary vitamin B6 intake modulates colonic inflammation in the IL10-/- model of inflammatory bowel disease. J Nutr Biochem (2013) 24:2138-43. doi:10.1016/j. jnutbio.2013.08.005

241. Fleischman NM, Das D, Kumar A, Xu Q, Chiu HJ, Jaroszewski L, et al. Molecular characterization of novel pyridoxal-5'-phosphate-dependent enzymes from the human microbiome. Protein Sci (2014) 23:1060-76. doi:10.1002/pro. 2493

242. D'Aimmo MR, Mattarelli P, Biavati B, Carlsson NG, Andlid T. The potential of bifidobacteria as a source of natural folate. J Appl Microbiol (2012) 112:975-84. doi:10.1111/j.1365-2672.2012.05261.x

243. de Crecy-Lagard V. Identification of genes encoding tRNA modification enzymes by comparative genomics. Methods Enzymol (2007) 425:153-83. doi:10.1016/S0076-6879(07)25007-4

244. Battat R, Kopylov U, Szilagyi A, Saxena A, Rosenblatt DS, Warner M, et al. Vitamin B12 deficiency in inflammatory bowel disease: prevalence, risk factors, evaluation, and management. Inflamm Bowel Dis (2014) 20:1120-8. doi:10.1097/MIB.0000000000000024

245. Yakut M, Ustun Y, Kabacam G, Soykan I. Serum vitamin B12 and folate status in patients with inflammatory bowel diseases. Eur J Intern Med (2010) 21:320-3. doi:10.1016/j.ejim.2010.05.007
246. Wang T, Zhang HP, Zhang X, Liang ZA, Ji YL, Wang G. Is folate status a risk factor for asthma or other allergic diseases? Allergy Asthma Immunol Res (2015) 7:538-46. doi:10.4168/aair.2015.7.6.538

247. Beulens JW, Booth SL, van den Heuvel EG, Stoecklin E, Baka A, Vermeer C. The role of menaquinones (vitamin $\mathrm{K}(2)$ ) in human health. Br J Nutr (2013) 110:1357-68. doi:10.1017/S0007114513001013

248. Hill MJ. Intestinal flora and endogenous vitamin synthesis. Eur J Cancer Prev (1997) 6(Suppl 1):S43-5. doi:10.1097/00008469-199703001-00009

249. Nowak JK, Grzybowska-Chlebowczyk U, Landowski P, SzaflarskaPoplawska A, Klincewicz B, Adamczak D, et al. Prevalence and correlates of vitamin $\mathrm{K}$ deficiency in children with inflammatory bowel disease. Sci Rep (2014) 4:4768. doi:10.1038/srep04768

250. Shiraishi E, Iijima H, Shinzaki S, Nakajima S, Inoue T, Hiyama S, et al. Vitamin $\mathrm{K}$ deficiency leads to exacerbation of murine dextran sulfate sodium-induced colitis. J Gastroenterol (2016) 51:346-56. doi:10.1007/s00535-015-1112-x

251. Kaitha S, Bashir M, Ali T. Iron deficiency anemia in inflammatory bowel disease. World J Gastrointest Pathophysiol (2015) 6:62-72. doi:10.4291/wjgp. v6.i3.62

252. Kulnigg S, Gasche C. Systematic review: managing anaemia in Crohn's disease. Aliment Pharmacol Ther (2006) 24:1507-23. doi:10.1111/j. 1365-2036.2006.03146.x

253. Stein J, Dignass AU. Management of iron deficiency anemia in inflammatory bowel disease - a practical approach. Ann Gastroenterol (2013) 26:104-13.

254. Werner T, Wagner SJ, Martinez I, Walter J, Chang JS, Clavel T, et al. Depletion of luminal iron alters the gut microbiota and prevents Crohn's disease-like ileitis. Gut (2011) 60:325-33. doi:10.1136/gut.2010.216929

255. Carrier JC, Aghdassi E, Jeejeebhoy K, Allard JP. Exacerbation of dextran sulfate sodium-induced colitis by dietary iron supplementation: role of NF-kappaB. Int J Colorectal Dis (2006) 21:381-7. doi:10.1007/s00384-0050011-7

256. Dostal A, Lacroix C, Pham VT, Zimmermann MB, Del'homme C, BernalierDonadille $\mathrm{A}$, et al. Iron supplementation promotes gut microbiota metabolic activity but not colitis markers in human gut microbiota-associated rats. Br J Nutr (2014) 111:2135-45. doi:10.1017/S000711451400021X

257. Barrett CW, Short SP, Williams CS. Selenoproteins and oxidative stressinduced inflammatory tumorigenesis in the gut. Cell Mol Life Sci (2017) 74:607-16. doi:10.1007/s00018-016-2339-2

258. Ojuawo A, Keith L. The serum concentrations of zinc, copper and selenium in children with inflammatory bowel disease. Cent Afr J Med (2002) 48:116-9.

259. Kaushal N, Kudva AK, Patterson AD, Chiaro C, Kennett MJ, Desai D, et al. Crucial role of macrophage selenoproteins in experimental colitis. J Immunol (2014) 193:3683-92. doi:10.4049/jimmunol.1400347

260. Norton RL, Hoffmann PR. Selenium and asthma. Mol Aspects Med (2012) 33:98-106. doi:10.1016/j.mam.2011.10.003

261. Michielan A, D’Inca R. Intestinal permeability in inflammatory bowel disease: pathogenesis, clinical evaluation, and therapy of leaky gut. Mediators Inflamm (2015) 2015:628157. doi:10.1155/2015/628157

262. Ariaee N, Farid R, Shabestari F, Shabestari M, Jabbari Azad F. Trace elements status in sera of patients with allergic asthma. Rep Biochem Mol Biol (2016) 5:20-5.

263. Reeves PG, Nielsen FH, Fahey GC Jr. AIN-93 purified diets for laboratory rodents: final report of the American Institute of Nutrition ad hoc writing committee on the reformulation of the AIN-76A rodent diet. J Nutr (1993) 123:1939-51.

Conflict of Interest Statement: The authors declare that the research was conducted in the absence of any commercial or financial relationships that could be construed as a potential conflict of interest.

Copyright $\odot 2017$ Statovci, Aguilera, MacSharry and Melgar. This is an open-access article distributed under the terms of the Creative Commons Attribution License (CC $B Y)$. The use, distribution or reproduction in other forums is permitted, provided the original author(s) or licensor are credited and that the original publication in this journal is cited, in accordance with accepted academic practice. No use, distribution or reproduction is permitted which does not comply with these terms. 